OPEN ACCESS

Edited by:

Marian Elizabeth Ludgate, Cardiff University, United Kingdom

Reviewed by: Susanne Neumann, National Institutes of Health $(\mathrm{NIH})$,

United States

Akira Sugawara,

Tohoku University, Japan

${ }^{*}$ Correspondence:

Willem A. Dik

w.dik@erasmusmc.n

Specialty section: This article was submitted to

Thyroid Endocrinology,

a section of the journal

Frontiers in Endocrinology

Received: 21 October 2020 Accepted: 21 December 2020 Published: 15 February 2021

Citation:

Virakul S, Somparn P, Pisitkun T, van der Spek PJ, Dalm VASH,

Paridaens $D$, van Hagen PM, Hirankarn N, Palaga T and Dik WA

(2021) Integrative Analysis of Proteomics and DNA Methylation in Orbital Fibroblasts From Graves' Ophthalmopathy.

Front. Endocrinol. 11:619989. doi: 10.3389/fendo.2020.619989

\section{Integrative Analysis of Proteomics and DNA Methylation in Orbital Fibroblasts From Graves' Ophthalmopathy}

Sita Virakul ${ }^{1}$, Poorichaya Somparn ${ }^{2,3}$, Trairak Pisitkun $^{2}$, Peter J. van der Spek ${ }^{4}$, Virgil A. S. H. Dalm ${ }^{5,6}$, Dion Paridaens ${ }^{7,8}$, P. Martin van Hagen ${ }^{5,6,7}$, Nattiya Hirankarn ${ }^{9}$, Tanapat Palaga ${ }^{1}$ and Willem A. Dik ${ }^{5 *}$

${ }^{1}$ Department of Microbiology, Faculty of Science, Chulalongkorn University, Bangkok, Thailand, ${ }^{2}$ Center of Excellence in Systems Biology, Research affairs, Faculty of Medicine, Chulalongkorn University, Bangkok, Thailand, ${ }^{3}$ Translational Research in Inflammation and Immunology Research Unit (TRIRU), Department of Microbiology, Faculty of Medicine, Chulalongkorn University, Bangkok, Thailand, ${ }^{4}$ Department of Bioinformatics, Erasmus University Medical Center, Rotterdam, Netherlands, ${ }^{5}$ Department of Immunology, Laboratory Medical Immunology, Erasmus University Medical Center, Rotterdam, Netherlands, ${ }^{6}$ Department of Internal Medicine, Division of Clinical Immunology, Erasmus University Medical Center, Rotterdam, Netherlands, ${ }^{7}$ Rotterdam Eye Hospital, Rotterdam, Netherlands, ${ }^{8}$ Department of Ophthalmology, Erasmus Medical Center, Rotterdam, Netherlands, ${ }^{9}$ Center of Excellence in Immunology and Immune Mediated Diseases, Department of Microbiology, Faculty of Medicine, Chulalongkorn University, Bangkok, Thailand

Background: Graves' ophthalmopathy (GO) is a frequent extrathyroidal complication of Graves' hyperthyroidism. Orbital fibroblasts contribute to both orbital tissue inflammation and remodeling in GO, and as such are crucial cellular elements in active GO and inactive GO. However, so far it is largely unknown whether GO disease progression is associated with functional reprogramming of the orbital fibroblast effector function. Therefore, the aim of this study was to compare both the proteome and global DNA methylation patterns between orbital fibroblasts isolated from active $\mathrm{GO}$, inactive $\mathrm{GO}$ and healthy controls.

Methods: Orbital fibroblasts from inactive $\mathrm{GO}(n=5)$, active $\mathrm{GO}(\mathrm{n}=4)$ and controls $(n=5)$ were cultured and total protein and DNA was isolated. Labelled and fractionated proteins were analyzed with a liquid chromatography tandem-mass spectrometer (LC-MS/MS). Data are available via ProteomeXchange with identifier PXD022257. Furthermore, bisulphite-treated DNA was analyzed for methylation pattern with the Illumina Infinium Human Methylation 450K beadchip. In addition, RNA was isolated from the orbital fibroblasts for real-time quantitative (RQ)-PCR. Network and pathway analyses were performed.

Results: Orbital fibroblasts from active GO displayed overexpression of proteins that are typically involved in inflammation, cellular proliferation, hyaluronan synthesis and adipogenesis, while various proteins associated with extracellular matrix (ECM) biology and fibrotic disease, were typically overexpressed in orbital fibroblasts from inactive GO. Moreover, orbital fibroblasts from active GO displayed hypermethylation of genes that linked to inflammation and hypomethylated genes that linked to adipogenesis and autoimmunity. Further analysis revealed networks that contained molecules to which 
both hypermethylated and hypomethylated genes were linked, including NF- $\mathrm{NB}$, ERK1/2, Alp, RNA polymerase II, Akt and IFN $\alpha$. In addition, NF- $\mathrm{KB}$, Akt and IFN $\alpha$ were also identified in networks that were derived from the differentially expressed proteins. Generally, poor correlation between protein expression, DNA methylation and mRNA expression was observed.

Conclusions: Both the proteomics and DNA methylation data support that orbital fibroblasts from active GO are involved in inflammation, adipogenesis, and glycosaminoglycan production, while orbital fibroblasts from inactive disease are more skewed towards an active role in extracellular matrix remodeling. This switch in orbital fibroblast effector function may have therapeutic implications and further studies into the underlying mechanism are thus warranted.

Keywords: graves' ophthalmopathy, orbital fibroblast, proteomics, DNA methylation, epigenetics

\section{INTRODUCTION}

Fibroblasts are crucial for maintaining tissue homeostasis, and are major producers of important cellular mediators for inflammatory and tissue remodeling processes during normal healing responses, but also under pathological conditions, including chronic inflammatory and fibrotic diseases (1). Chronic tissue inflammation and fibrosis are characterized by excessive fibroblast accumulation in affected tissues (1). Fibroblast accumulation occurs through different mechanisms, including enhanced proliferation by tissue resident CD34fibroblasts, recruitment of fibrocytes (a population of circulating cells with fibroblast-like properties that express $\mathrm{CD}_{3} 4^{+}$and extracellular matrix (ECM) molecules) and diminished apoptosis/prolonged survival (2-4). These fibroblasts can alter their phenotype and effector functions, as evidenced by their differentiation into myofibroblasts $(5,6)$. Myofibroblasts are considered to represent the end-effector cells in fibrotic reactions. Myofibroblasts express $\alpha$-smooth muscle actin that facilitates cellular contraction and tissue distortion and actively produce high amounts of ECM molecules, such as collagen and hyaluronan (1).

Graves' ophthalmopathy (GO) is a disease of the orbital softtissues surrounding the eyes, and affects up to $50 \%$ of patients with Graves' disease (GD) (7). In general, GO patients first suffer from an initial phase of progressive disease (the 'active' phase) that is characterized by active inflammation (8). This active phase may last for months after which the activity subsides and progresses to a phase of slow spontaneous recovery. This 'chronic' phase may take months to years and is associated with pathological tissue alterations, including adipose tissue expansion, excessive hyaluronan accumulation and fibrosis (8). The orbital tissue alterations are largely responsible for several morbidities such as proptosis, chronic eye movement dysfunction, and eventually determines the 'severity' of GO (7). Previously, protein expression profiles of orbital tissues from GO with different disease activity and smoking status revealed differences in several proteins involved in inflammation and adipogenesis $(9,10)$. However, those proteins could not be specifically linked to their pathogenic cellular source.

Orbital fibroblasts represent the main effector cells in GO as they are crucially involved in regulation of both the local inflammatory and tissue remodeling responses. The effector functions of the orbital fibroblasts are in turn affected by several mediators, including the thyrotropin receptor (TSHR) stimulatory autoantibodies, cytokines, growth factors and physical cellular interactions (8). Importantly, orbital fibroblasts from GO patients may react in a different way to such stimuli than orbital fibroblasts isolated from healthy orbital tissue. For instance a stronger upregulation of CD40, Thy1, IGF1R and BAFF by GO orbital fibroblasts was reported (1114). Moreover, orbital fibroblasts isolated from active GO display enhanced secretion of certain pro-inflammatory mediators in comparison to orbital fibroblasts from control tissue, even in the absence of further in vitro stimulation $(15,16)$. Furthermore, differentiation of orbital fibroblasts into adipocytes and profibrotic myofibroblasts appears to be more restricted to the late inactive stage of disease and is associated with increased TSHR expression by these cells $(17,18)$.

Gradually, epigenetic regulation (e.g. histone modification, DNA methylation and non-coding RNA) has become the subject of studies in primary fibroblasts isolated from different fibroproliferative diseases, including idiopathic pulmonary fibrosis (IPF) and systemic sclerosis (SSc) (4, 19-22). Fibroblasts from IPF and SSc have altered DNA methylation profiles, which contribute to the regulation of gene transcription in these cells $(19,20)$. In GO, differential gene expression has been demonstrated in orbital tissue, suggesting a role for epigenetics in the pathogenesis of GO (23). However, data on DNA methylation in orbital fibroblasts from GO is lacking to date. Insight in this could help to develop novel therapeutic options that target aberrant epigenetic modifications in GO. Here we conducted a study to compare the proteome of orbital fibroblasts isolated from active GO, inactive GO and control orbital tissue and integrated these data with global DNA methylation analysis performed on the same orbital fibroblasts. 


\section{MATERIAL AND METHODS}

\section{Orbital Fibroblast Isolation From Orbital Tissue}

Orbital fibroblasts were cultured from four patients with GO in an active stage (clinical activity score $(\mathrm{CAS}) \geq 3 / 7$ ) and five patients with GO in an inactive stage of disease (CAS < 3/7) $(24)$, who underwent orbital decompression surgery. In addition, orbital fibroblasts were cultured from five controls without thyroid or inflammatory disease that underwent orbital surgery for other reasons, as described previously (25). GO patients were euthyroid and had not received immunosuppressive treatment for at least three months prior to orbital decompression surgery. Further patient characteristics are given in Table 1. All orbital tissues were obtained at the Rotterdam Eye Hospital (Rotterdam, the Netherlands), after informed consent and in accordance with the principles of the Declaration of Helsinki. Approval was given by the local medical ethics committee (protocol ID-2007-01). Orbital fibroblasts were cultured in Dulbecco's modified Eagle's medium (DMEM) supplemented with $10 \%$ fetal calf serum (FCS) and antibiotics (penicillin and streptomycin; Cambrex BioWhittaker, Verviers, Belgium) (25). Orbital fibroblasts were serially passaged with gentle treatment of trypsin/EDTA and used for experiments between the $2^{\text {nd }}$ and $6^{\text {th }}$ passage.

\section{Proteome Analysis}

Protein Extraction, Peptide Preparation and Labeling

Orbital fibroblasts from four patients with GO at an active stage and five GO patients at an inactive stage of disease, and five controls were included in this experiment. Orbital fibroblasts $(5 \mathrm{x}$ $10^{6}$ cells) were obtained and pelleted after which Halt ${ }^{\mathrm{TM}}$ Protease Inhibitor Cocktail and Phosphatase Inhibitor Cocktail (Thermo Fisher Scientific, Rockford, IL) was added before digestion and homogenization in 5\% sodium deoxycholate with a sonicator. Protein concentration was determined with Pierce ${ }^{\mathrm{TM}}$ BCA Protein Assay Kit (Thermo Fisher Scientific, Rockford, IL). For peptide preparation, $100 \mu \mathrm{g}$ of protein was digested with $2 \mu \mathrm{g}$ trypsin and labelled with 10-plex tandem mass tag (TMT) reagent according to the manufacturer's protocol (Thermo Fisher Scientific, Rockford, IL). Afterwards, the peptide mixture was passed

TABLE 1 | Patients and controls data.

\begin{tabular}{lccc}
\hline Participants & Cell ID & Age & Gender \\
\hline Healthy control & COF-3 & 48 & Female \\
& COF-4 & 82 & Female \\
COF-7 & 80 & Female \\
COF-9 & 59 & Female \\
Inactive GO & COF-10 & 37 & Female \\
& GO-11 & 43 & Female \\
& GO-27 & 69 & Female \\
GO-31 & 46 & Female \\
Active GO & GO-56 & 51 & Female \\
& GO-89 & 32 & Female \\
& GO-19 & 31 & Female \\
& GO-37 & 62 & Female \\
& GO-88 & 77 & Male \\
& GO-90 & 84 & Female
\end{tabular}

through the Pierce High pH Reversed-Phase Peptide Fractionation Kit (Thermo Fisher Scientific, Rockford, IL).

\section{Peptide Analysis}

The labelled fractionated peptides were analyzed with a liquid chromatography tandem-mass spectrometer (LC-MS/MS) (Q Exactive Plus mass spectrometer; Thermo Scientific, San Jose, CA). The LC-MS/MS methods included a full MS scan at a resolution of 70,000 followed by 10 data-dependent MS2 scans at a resolution of 37,500. The normalized collision energy of higher-energy collisional dissociation (HCD) fragmentation was set at $28 \%$. MS scan range of 400 to $1,600 \mathrm{~m} / \mathrm{z}$ was selected and precursor ions with unassigned charge states, a charge state of +1 and a charge state of greater than +8 were excluded. Proteome discoverer 2.1 software (Thermo Scientific, San Jose, CA) was used to analyze the MS raw data files with database containing forward and reverse peptide sequences from the human Uniprot Database. The search parameters were set for the fix modifications of carbamidomethylation of cysteine $(+57.02146 \mathrm{Da})$ and TMT modifications $(+229.2634 \mathrm{Da})$ at $\mathrm{N}$-terminal and lysine, while oxidation of methionine $(+15.99491 \mathrm{Da})$ was set for the variable modification. A maximum of four modifications and two missed cleavages per peptide were allowed. Parent and fragment monoisotopic mass errors were set at $10 \mathrm{ppm}$ and $0.2 \mathrm{Da}$, respectively. A target-decoy approach was used to limit the false discovery rate (FDR) of the identified peptides to less than $1 \%$. Differential protein expression was compared between orbital fibroblasts isolated from active and inactive GO by Student's ttest. The mass spectrometry proteomics data have been deposited to the ProteomeXchange Consortium via the PRIDE [1] partner repository with the dataset identifier PXD022257. Network, pathway and functional analysis were further performed on these differential expressed proteins using Ingenuity (Qiagen) filtering only for those networks and pathways that are based on experimentally obtained information.

\section{DNA Methylation Analysis}

Total DNA was extracted from orbital fibroblasts of active GO $(\mathrm{n}=4)$, inactive GO $(\mathrm{n}=4)$ and controls $(\mathrm{n}=4)$. Global DNA methylation was measured using the Illumina Infinium Human Methylation $450 \mathrm{~K}$ beadchip on bisulphite-treated DNA. DNA methylation analysis was performed by GenomeStudio methylation analysis package. Methylation level ranges from 0 (unmethylated) to 1 (fully methylated). Differential DNA methylation levels/patterns were analyzed by two approaches; 1) genes with differential DNA methylation using FDR $<0.05$, and 2) differences in DNA methylation level of at least 2-fold between active and inactive GO. This was followed by network, pathway and functional analysis using Ingenuity (Qiagen) filtering only for those networks and pathways that are based on experimentally obtained information.

\section{mRNA Expression by Orbital Fibroblasts}

Messenger RNA was isolated (GenElute Mammalian Total RNA Miniprep Kit; Sigma-Aldrich, St. Louis, MO, USA) from orbital fibroblasts from the same culture experiment as used for the 
proteome and DNA methylation studies. The isolated mRNA was converted into $\mathrm{CDNA}$ and gene expression was determined by real-time quantitative (RQ)-PCR (QuantStudio 5 Real-Time PCR System; Applied Biosystems, Waltham, MA) and normalized to the control gene $A B L$, as described previously (25). Primer-probe combinations $(A B L)$ and TaqMan gene expression assays (Life technologies, Foster, CA) used are listed in Supplementary Table 1. Data from mRNA expression was analyzed using ANOVA and subsequently analyzed with the Mann Whitney U test. A P-value $<0.05$ was considered statistically significant.

\section{RESULTS}

\section{Proteome Analysis in Orbital Fibroblasts}

Twenty-five proteins differed significantly in their expression level between orbital fibroblasts from patients with active GO versus inactive GO (Supplementary Table 2). Cluster analysis revealed that the differentially expressed proteins clustered into three main groups (Figure 1A, indicated as cluster 1, cluster 2 and cluster 3$)$. Proteins $(n=6)$ in cluster 2 displayed higher expression in orbital fibroblasts from inactive GO compared to orbital fibroblasts from active GO and controls (Figure 1B). The proteins $(n=16)$ in cluster 3 were higher expressed in orbital fibroblasts from active GO compared to inactive GO and controls (Figure 1C). The proteins $(n=3)$ in cluster 1 were expressed at slightly higher level in orbital fibroblasts from active GO than orbital fibroblasts from inactive GO and controls.

\section{Validation of Differential Protein Expression by RQ-PCR}

For eleven of the proteins found to be differentially expressed (4 up-regulated and 7 down-regulated in inactive GO orbital fibroblasts compared to active GO) the expression levels of the corresponding mRNA molecules were determined by RQ-PCR (Figures 1B, C). From the 4 proteins (PSMB4, FBN2, COL6A1 and NCAM2) upregulated, only NCAM2 mRNA was significantly higher expressed $(\mathrm{P}<0.05)$ in orbital fibroblasts from inactive GO compared to active GO (Figure 1B), while the mRNA levels of PSMB4, FBN2 and COL6A1 only showed a trend to higher expression in inactive GO orbital fibroblasts compared with active GO orbital fibroblasts (Figure 1B). Of the 7 proteins (PACSIN3, NFKB1, SMC3, GFER, GSDMD, UGDH and MT1X) that were expressed at significantly lower levels in orbital fibroblasts from inactive GO, none of the corresponding mRNAs was significantly decreased in inactive GO (Figure 1C). Unexpectedly, NFKB1 mRNA expression was significantly upregulated in inactive $\mathrm{GO}$ orbital fibroblasts compared to active GO (Figure 1C).

\section{Orbital Fibroblast Expressed Proteins in Active GO Relate to Inflammation, Hyaluronan and Adipogenesis}

Proteins overexpressed by orbital fibroblasts from active GO related to inflammation, hyaluronan synthesis and adipogenesis.
One of the inflammation related proteins highly expressed in active GO orbital fibroblasts was NFKB1 (Figure 1C). The NFKB1 $105 \mathrm{kD}$ protein can be processed by the $26 \mathrm{~S}$ proteasome into the DNA binding p50 subunit of the transcription factor NF- $\kappa B(26)$. $\mathrm{NF}-\kappa \mathrm{B}$ stimulates expression of genes involved in inflammation in many different cell types, including orbital fibroblasts $(27,28)$. The NFKB1 subunit exerts a protective role by dampening inflammation (29). Therefore, upregulation of NFKB1 may represent a counter regulatory mechanism to control the inflammatory response in orbital fibroblasts from active GO $(8,11)$.

ECM and fibrosis related proteins that were overexpressed in orbital fibroblasts from active GO included structural maintenance of chromosomes 3 (SMC3), growth factor, augmenter of liver regeneration (GFER) and uridine diphosphate-glucose dehydrogenase (UGDH) (Figure 1C). $\mathrm{UGDH}$ is involved in the biosynthesis of glycosaminoglycans (GAG), such as hyaluronan, chondroitin sulfate and heparan sulfate and was previously found elevated in urine from patients with active GO (30). Moreover, UGDH was found to be expressed at higher levels in orbital fibroblasts than in fibroblasts from other anatomical regions (31). This indicates that orbital fibroblasts in active GO acquire a phenotype very well equipped for GAG synthesis (32). Orbital fibroblasts from active GO also produced more protein kinase $c$ and casein kinase substrate in neurons (PACSIN) 3, a protein involved in clathrin-mediated endocytosis that regulates glucose uptake by adipocytes $(33,34)$. The up-regulation of PACSIN3 in the active orbital fibroblasts may therefore relate to formation of adipocytes that finally accumulate in the inactive phase of GO (35).

\section{Orbital Fibroblast Expressed Proteins in Inactive GO Relate to Extracellular Matrix Biology}

Orbital fibroblasts from inactive GO overexpressed several proteins linked to ECM biology and fibrotic diseases. This included fibrillin-2 (FBN2), collagen type VI alpha 1 chain (COL6A1) and the neural adhesion molecule 2 (NCAM2) (Figure 1B) (36-39). FBN2 is involved in elastic fiber formation and is abundantly present in embryonic tissues, but is also elevated along with elastin in fibrotic tissue, for instance in systemic sclerosis $(36,40)$. Yet, data on elastin accumulation in orbital tissue from GO patients is lacking so far. The non-fibrillar collagen type VI is involved in structural organization of the ECM, for instance by interacting with a multitude of other key ECM components, including the fibrillary type- 1 and type 3 collagens and hyaluronan $(39,41$, 42). Increased COL6A1 tissue levels are present in lung fibrosis, liver fibrosis and keloid scarring (37-39). Furthermore, collagen type VI can bind a variety of different growth factors implicated in fibrosis, and as such serves as a reservoir that can regulate growth factor activity in the vicinity of fibroblasts and contribute to fibrosis $(39,42,43)$. Although data on collagen type VI in GO orbital tissue is lacking so far, several growth factors that bind collagen type VI, including PDGF-AB, PDGF- 
A

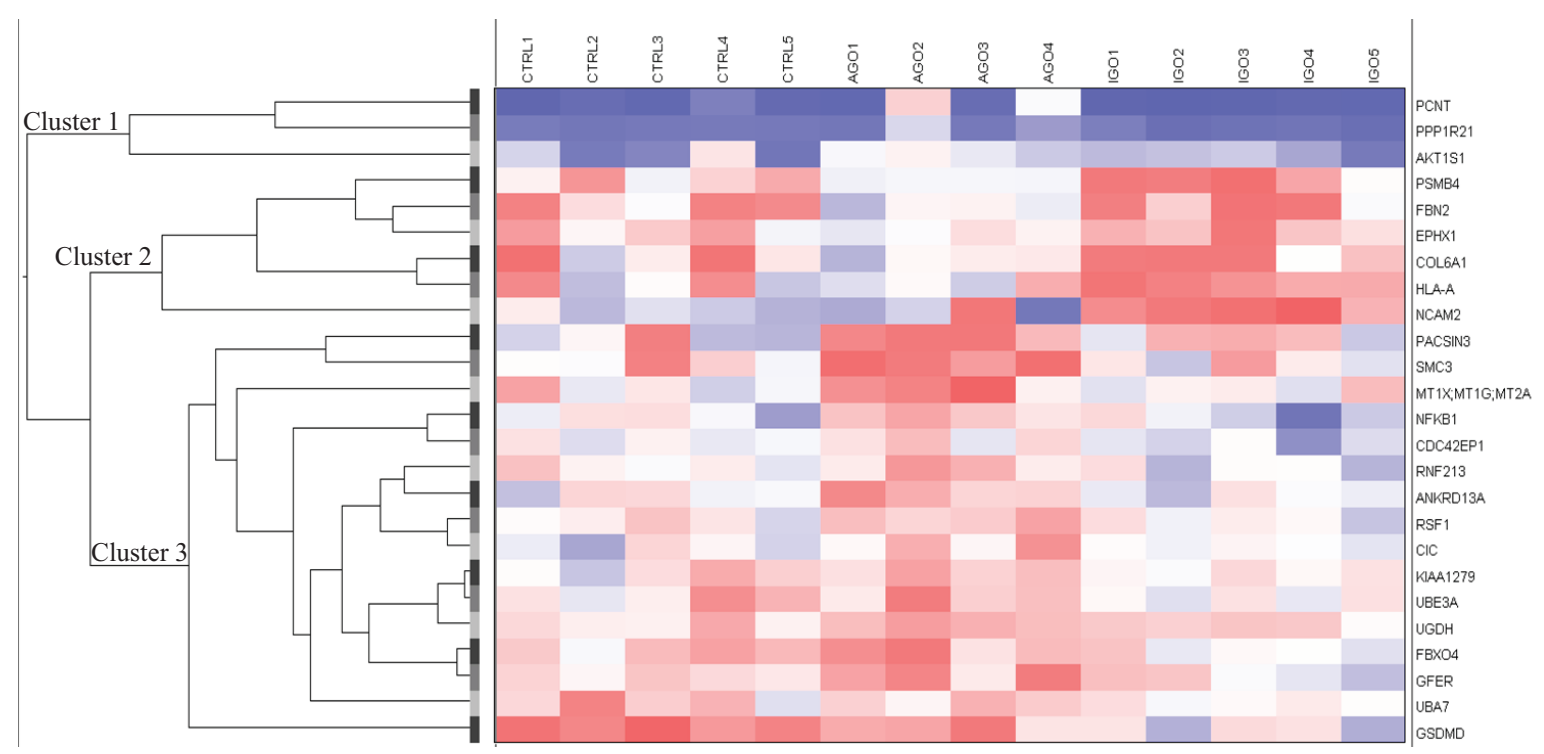

B
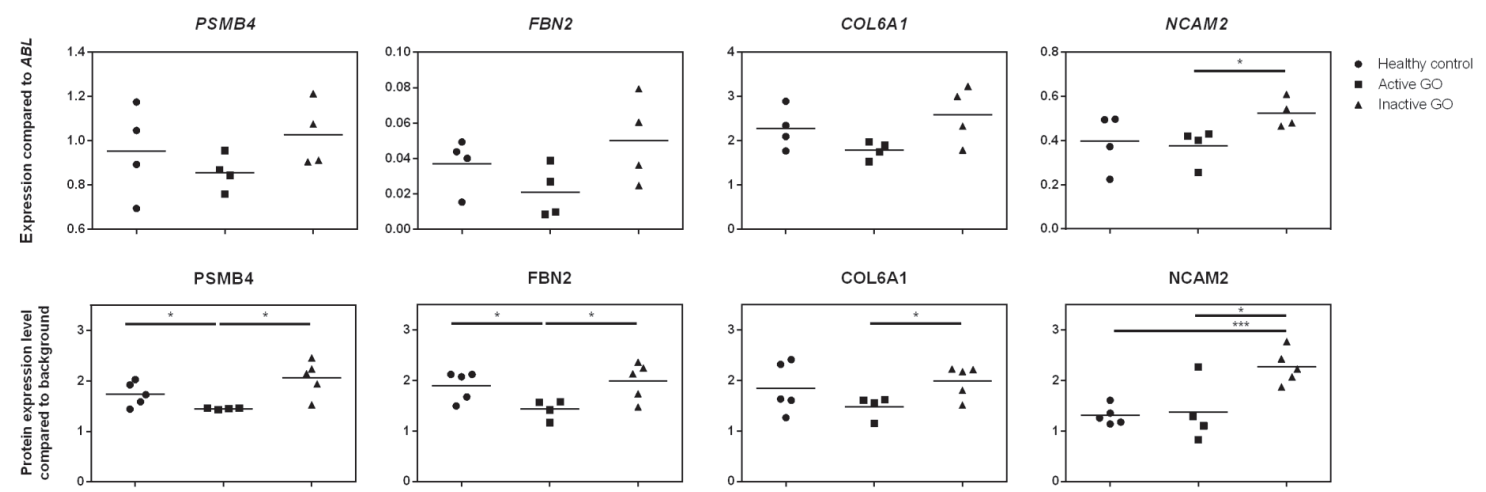

C

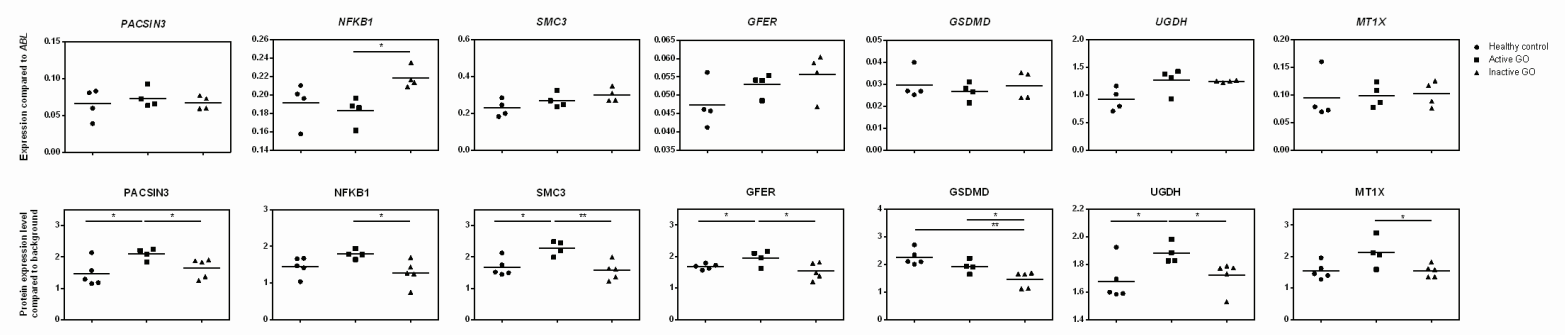

FIGURE 1 | Continued 
FIGURE 1 | Proteomic profiles of orbital fibroblasts from inactive GO, active GO and healthy controls. (A) Cluster analysis of the differential protein expression between orbital fibroblasts from patients with inactive GO $(n=5)$, active $G O(n=4)$ and healthy controls $(n=5)$. Differentially expressed proteins grouped in three main clusters. Proteins within cluster 1 proteins were expressed at slightly higher level in orbital fibroblasts from active GO compared with orbital fibroblasts from inactive GO and controls. Proteins within cluster 2 displayed higher expression in orbital fibroblasts from inactive GO compared with orbital fibroblasts from active $\mathrm{GO}$ and controls. Proteins within cluster 3 were expressed at a higher level in orbital fibroblasts from active GO compared to inactive GO and controls. (B) Gene and protein expression level from proteins within cluster 2. Protein expression levels were compared to high abundant protein expression level. Four proteins (PSMB4, FBN2, COL6A1 and NCAM2) up-regulated in inactive GO orbital fibroblasts compared to active GO were related to extracellular matrix biology and further determined by RQ-PCR. * and ${ }^{* \star *}$ indicate $\mathrm{p}$-value $<0.05$ and $<0.001$, respectively. Individual symbols represent orbital fibroblast cultures from individual patients. Horizontal bar depicts the median. (C) Gene and protein expression level from proteins within cluster 3. Protein expression levels were compared to high abundant protein expression level. Seven proteins (PACSIN3, NFKB1, SMC3, GFER, GSDMD, UGDH and MT1X) down-regulated in inactive GO orbital fibroblasts compared to active GO related to inflammation, hyaluronan and adipogenesis were determined by $R Q-P C R$. * and ${ }^{* *}$ indicate $p$-value $<0.05$ and $<0.01$, respectively. Individual symbols represent orbital fibroblast cultures from individual patients. Horizontal bar depicts the median.

$\mathrm{BB}$, and HGF have been linked to GO pathogenesis (44-46). Neural adhesion molecule 2 (NCAM2) was also higher expressed by orbital fibroblasts from inactive GO. NCAM2 can activate fibroblast growth factor receptor (FGFR), and recent studies demonstrated that FGFR activation in orbital fibroblasts stimulates hyaluronan synthesis and adipogenesis (47-49). Therefore, it can be postulated that in late inactive GO, orbital fibroblast-derived NCAM2 might be involved in adipogenesis and hyaluronan synthesis through FGFR activation. Clearly further detailed study on the role of the molecules we here found to be expressed at higher levels in orbital fibroblasts from inactive GO is required. Yet, our data strongly suggest that in the inactive stage of GO the orbital fibroblasts acquire effector functions that are strongly related to ECM remodeling.

\section{Proteome Pathway, Network and Functional Analysis}

The proteins differentially expressed between orbital fibroblasts from active GO and inactive GO were fed into Ingenuity with the aim to link these proteins to networks and pathways of interest to GO pathogenesis. The top two identified canonical pathways were UDP-D-xylose and UDP-D-glucuronate biosynthesis ( $\mathrm{p}$-value = $0.00217)$ and protein ubiquitination pathway ( $\mathrm{p}$-value $=0.00305)$ (Table 2). Moreover, all these proteins, except MT1X, were linked to 2 networks (Figure 2). The first network is associated with

TABLE 2 | Top 5 canonical pathways and diseases and bio-functions from the differentially expressed proteins.

Top Canonical Pathways

\begin{tabular}{|c|c|c|}
\hline Name & p-value & Overlap \\
\hline UDP-D-xylose and UDP-D-glucuronate & 0.00217 & $50.0 \%$ \\
\hline \multicolumn{3}{|l|}{ Biosynthesis } \\
\hline Protein Ubiquitination Pathway & 0.00305 & $1.1 \%$ \\
\hline $\begin{array}{l}\text { Crosstalk between Dendritic Cells and Natural } \\
\text { Killer Cells }\end{array}$ & 0.00418 & $2.2 \%$ \\
\hline $\begin{array}{l}\text { Altered T Cell and B Cell Signaling in } \\
\text { Rheumatoid Arthritis }\end{array}$ & 0.00427 & $2.2 \%$ \\
\hline OX40 Signaling Pathway & 0.00427 & $2.2 \%$ \\
\hline
\end{tabular}

Top Diseases and Bio Functions

Diseases and Disorders

\begin{tabular}{lcc}
\hline Name & p-value & \#Molecules \\
\hline Cancer & $0.00000287-0.049$ & 24 \\
Endocrine System Disorders & $0.00000287-0.0436$ & 24 \\
Organismal Injury and Abnormalities & $0.00000087-0.0498$ & 24 \\
Reproductive System Disease & $0.0000428-0.0436$ & 19 \\
Respiratory Disease & $0.0000551-0.0394$ & 13 \\
\hline
\end{tabular}

Molecular and Cellular Functions

Name

Cell-To-Cell Signaling and Interaction

Carbohydrate Metabolism

Cell Death and Survival

Cell Morphology

Cellular Assembly and Organization

p-value

$0.000469-0.0434$

$0.00111-0.0445$

$0.00111-0.0487$

$0.00111-0.0434$

$0.00111-0.0424$
Proteins (listing from the lowest p-value)

HLA-A, NFKB1, UBE3A, CDC42EP1, NCAM2, SMC3

UGDH, EPHX1, HLA-A, NFKB1

HLA-A, NFKB1, FBN2, PSMB4, GSDMD, SMC3, COL6A1, GFER, RSF1, AKT1S1, EPHX1, UBA7, UBE3A

NFKB1, PCNT, UBE3A, NCAM2, GFER, GSDMD, HLA-A, CDC42EP1

KIF1BP, ANKRD13A, CDC42EP1, NCAM2, NFKB1, UBE3A, GFER, PCNT, RSF1, FBXO4, HLA-A 
A

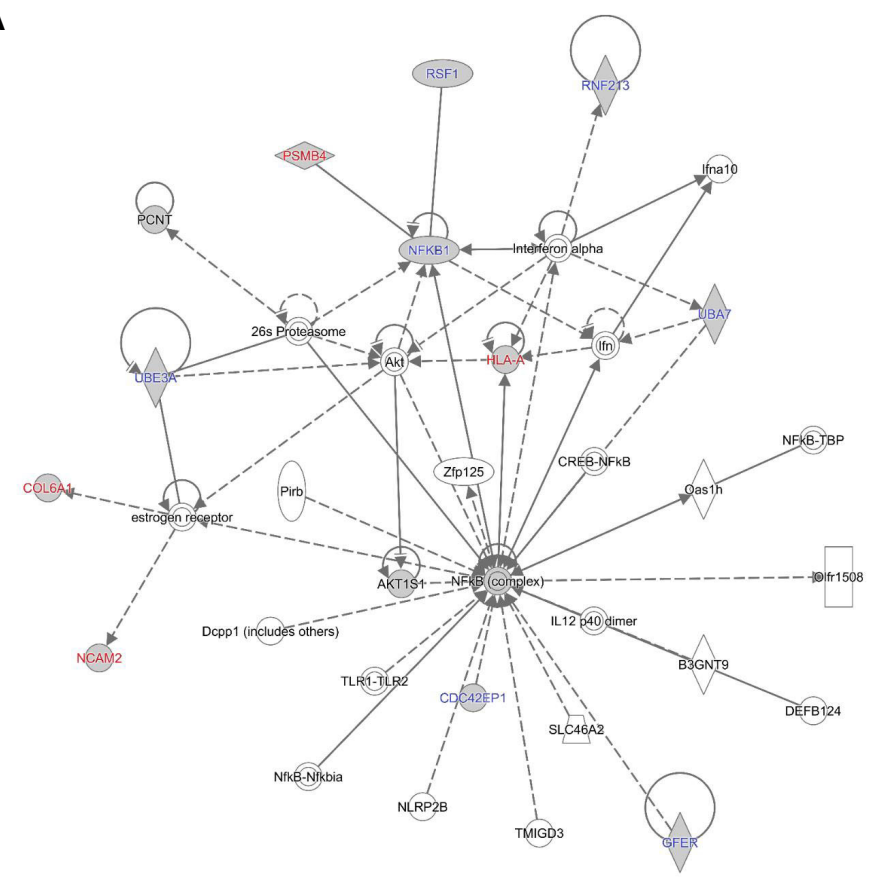

D 2000-2019 QIAGEN. All rights reserved

B

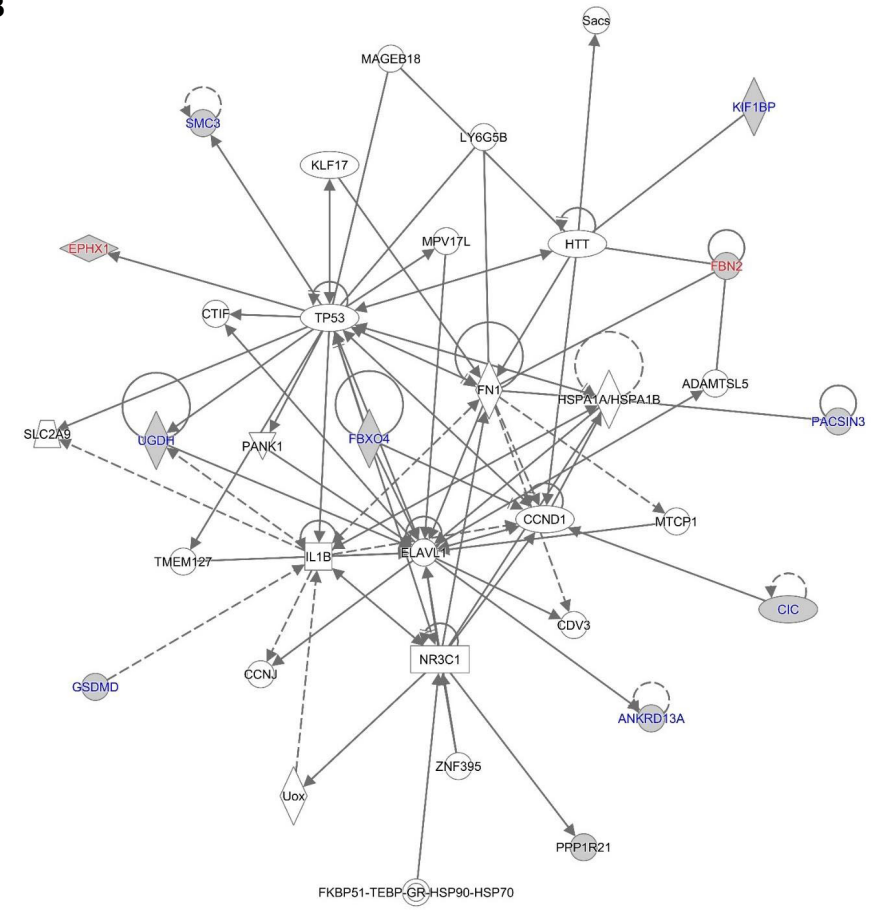

FIGURE 2 | Proteome based network analysis. (A) Network 1: linked to cellular development and connective tissue disorders. Differentially expressed proteins are highlighted in grey. The differentially expressed proteins labelled in red were the up-regulated while differentially expressed proteins labelled in blue were downregulated in inactive GO comparing to active GO orbital fibroblasts. (B) Network 2: linked to free radical scavenging, DNA replication, recombination and repair and cellular assembly and organization. Differentially expressed proteins are highlighted in grey. The differentially expressed proteins labelled in red were up-regulated while differentially expressed proteins labelled in blue were down-regulated in inactive GO comparing to active GO orbital fibroblasts. 


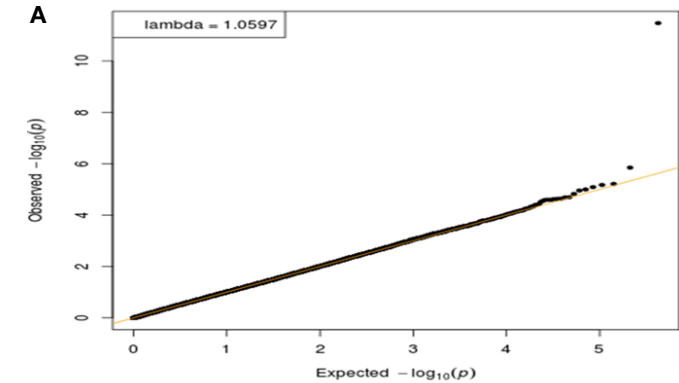

B
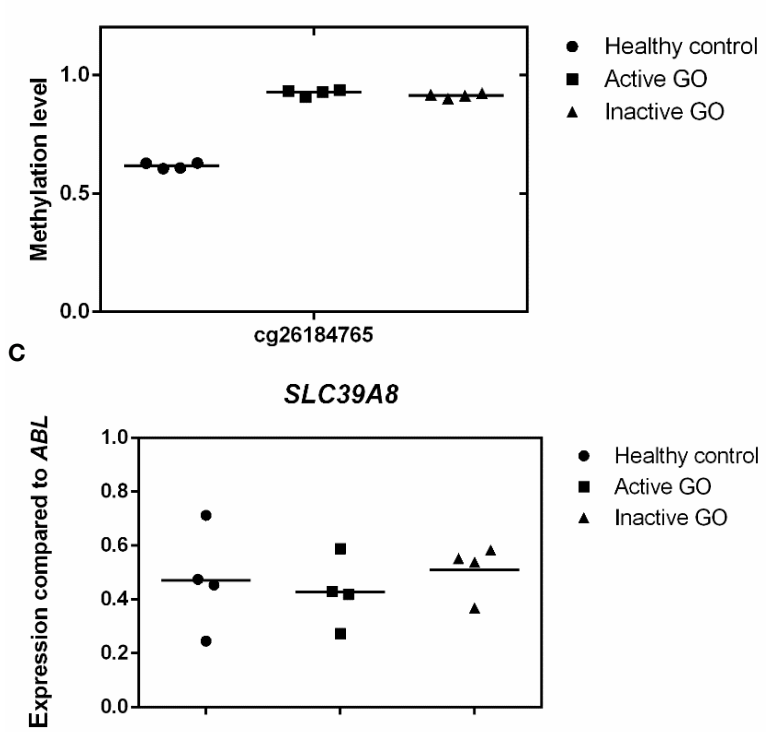

FIGURE 3 | Comparison of orbital fibroblast global DNA methylation profiles with FDR $<0.05$. (A) DNA methylation in active $\mathrm{GO}$ orbital fibroblasts $(n=4)$, inactive $\mathrm{GO}$ orbital fibroblasts $(n=4)$ and healthy control orbital fibroblasts $(n=4)$ were compared. Global DNA methylation was measured using the Illumina Infinium Human Methylation 450K beadchip on bisulphite-treated DNA and analyzed by GenomeStudio methylation analysis package. Genes with differential DNA methylation were further corrected for multiple testing using FDR < 0.05. (B) Methylation level of SLC39A8. Methylation level ranges from 0 (unmethylated) to 1 (fully methylated). Individual symbols represent orbital fibroblast cultures from individual patients. Horizontal bar depicts the median. (C) SLC39A8 expression was determined by real-time quantitative $(R Q)-P C R$ and normalized to the control gene $A B L$. Data from mRNA expression was analyzed using ANOVA and subsequently analyzed with the Mann Whitney $U$ test. Individual symbols represent orbital fibroblast cultures from individual patients. Horizontal bar depicts the median.

cellular development and connective tissue disorders (Figure 2A), while the second network is linked to free radical scavenging, DNA replication, recombination and repair and cellular assembly and organization (Figure 2B). In network 1, the differentially expressed proteins were linked with NF- $\kappa \mathrm{B}, \mathrm{Akt}$, 26s proteasome, interferon alpha and estrogen receptor (Figure 2A). On the other hand, the differentially expressed proteins in network 2 were linked to several transcriptional regulators, such as cellular tumor antigen p53 (TP53), huntingtin (HTT), cyclin D1 (CCND1), and also other (pathogenic) proteins including fibronectin 1 (FN1) and Hsp70binding protein 1 (HSPA) (Figure 2B).

\section{Global DNA Methylation Profile in Orbital Fibroblasts}

After adjustment for multiple testing using false discovery rate (FDR $<0.05)$, none of the genes were differentially methylated when comparing the orbital fibroblasts isolated from active GO ( $\mathrm{n}=4)$ and inactive GO patients $(\mathrm{n}=4)$, although hypermethylated GNAS (cg09885502) showed a trend to reach statistical significance $(F D R=0.0774)$ in inactive $\mathrm{GO}$ (Supplementary Figure 1). However, GNAS was not found differentially expressed at the protein level with the current technique used (Supplementary Figure 1). SLC39A8 was the only gene that showed statistically significant difference when comparing control orbital fibroblasts $(\mathrm{n}=4)$ with all GO patients (active and inactive GO; $\mathrm{n}=8)\left(\mathrm{FDR}=1.404 \times 10^{-6}\right)$ (Figure 3A), being hypermethylated in the 3'UTR region in the orbital fibroblasts from GO patients comparing to healthy control (Figure 3B). Although this could potentially be associated with decreased SLC39A8 gene expression on GO orbital fibroblasts, no difference in mRNA expression was detected between the orbital fibroblast from inactive GO, active GO and controls (Figure 3C). Neither was SLC39A8 protein detected by our current proteomics approach. Gene expression level of enzymes regulating DNA methylation, the writers, DNA methyltransferases (DNMTs), and the erasers, ten eleven translocation (TET), were further examined; however, the expression level of all DNMT and TET were not significantly different in orbital fibroblasts from GO and healthy controls (Supplementary Figure 2).

\section{Hypermethylated Genes in Orbital Fibroblasts From Active GO Patients}

We further analyzed differences in methylation level in a less stringent manner by applying a cut-off difference of more than 2 fold between active and inactive GO patients. This resulted in a total of 142 hits, corresponding to 115 coding genes, that were hypermethylated in the orbital fibroblasts from active GO patients (Figure 4 and Supplementary Table 3). Among the top 10 genes (with the fold differences ranging approximately from 3.1 to 6.9fold), the highest fold difference was detected by a single probe located in the gene body of WDR8 (Supplementary Figure 3 and Supplementary Table 3). Several other genes were detected by more than one probe including Mir548F5, MAB21L1, HTATIP2, TTC12, NIPAL2, TRIM2, PAQR5, OR2L13, RPH3AL, GPR6, MYOM2, DGKQ, ZNF234 and SPAG1 (Supplementary Figure 3).

\section{Hypomethylated Genes in Orbital Fibroblasts From Active GO Patients}

Applying the cut-off difference of more than 2-fold between active and inactive GO patients yielded 66 hits, corresponding for 63 genes, that were hypomethylated in the orbital fibroblasts from active GO compared with orbital fibroblasts from inactive GO patients (Figure 5 and Supplementary Table 4). The gene set hypomethylated in active GO orbital fibroblasts comprised a.o.: RNF168 (with the highest fold change of 5.08-fold, as 


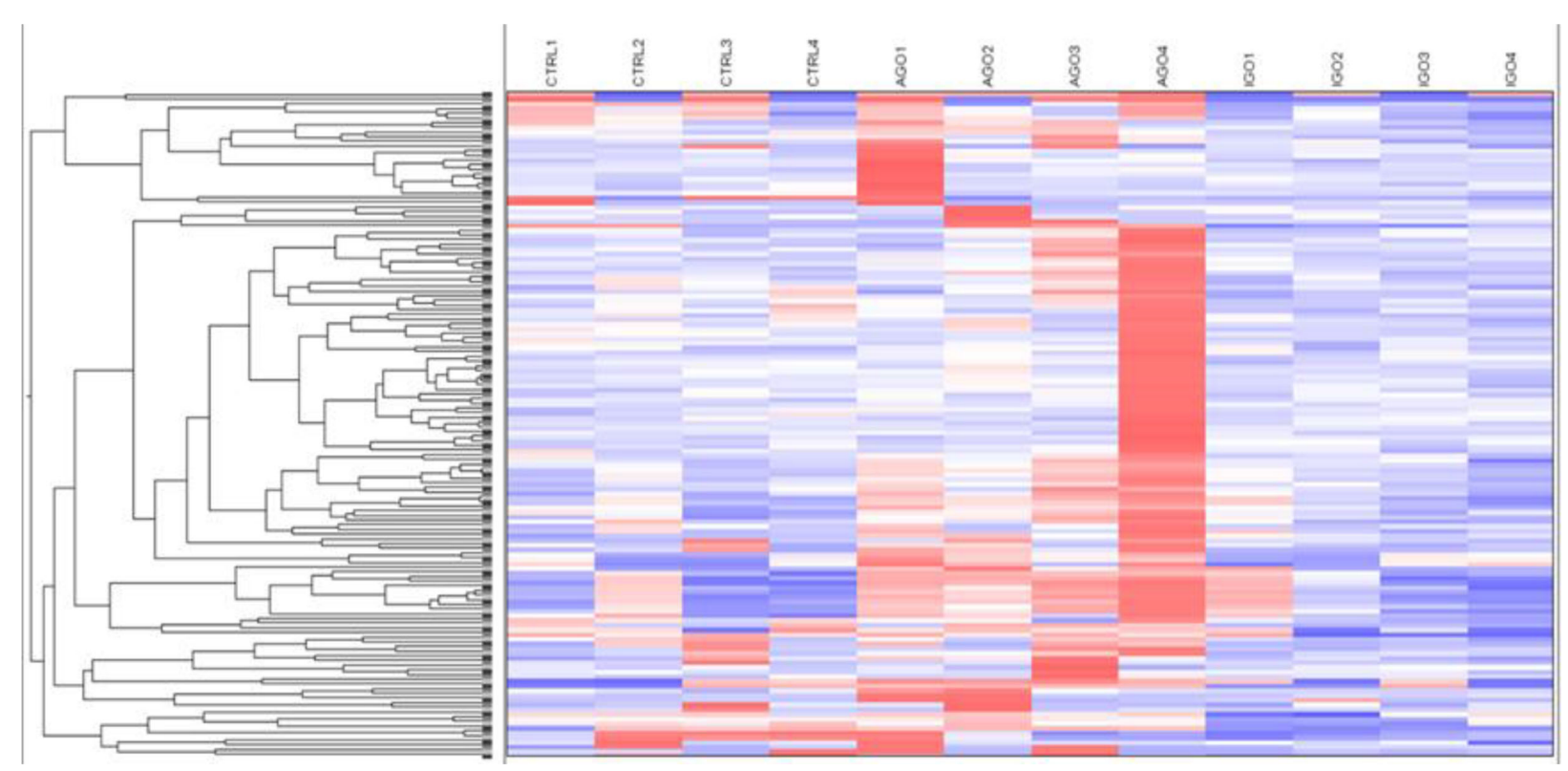

FIGURE 4 | Hypermethylated genes in orbital fibroblasts from active GO in comparison to orbital fibroblasts from inactive GO and healthy controls with a fold difference $\geq 2$. DNA methylation in active $G O$ orbital fibroblasts $(n=4)$ was compared with inactive $G O$ orbital fibroblasts $(n=4)$. Global DNA methylation was measured using the Illumina Infinium Human Methylation 450K beadchip on bisulphite-treated DNA and analyzed by GenomeStudio methylation analysis package. Hypermethylated genes with differences in DNA methylation level of at least 2-fold in active GO orbital fibroblasts were clustered as shown in the heatmap.

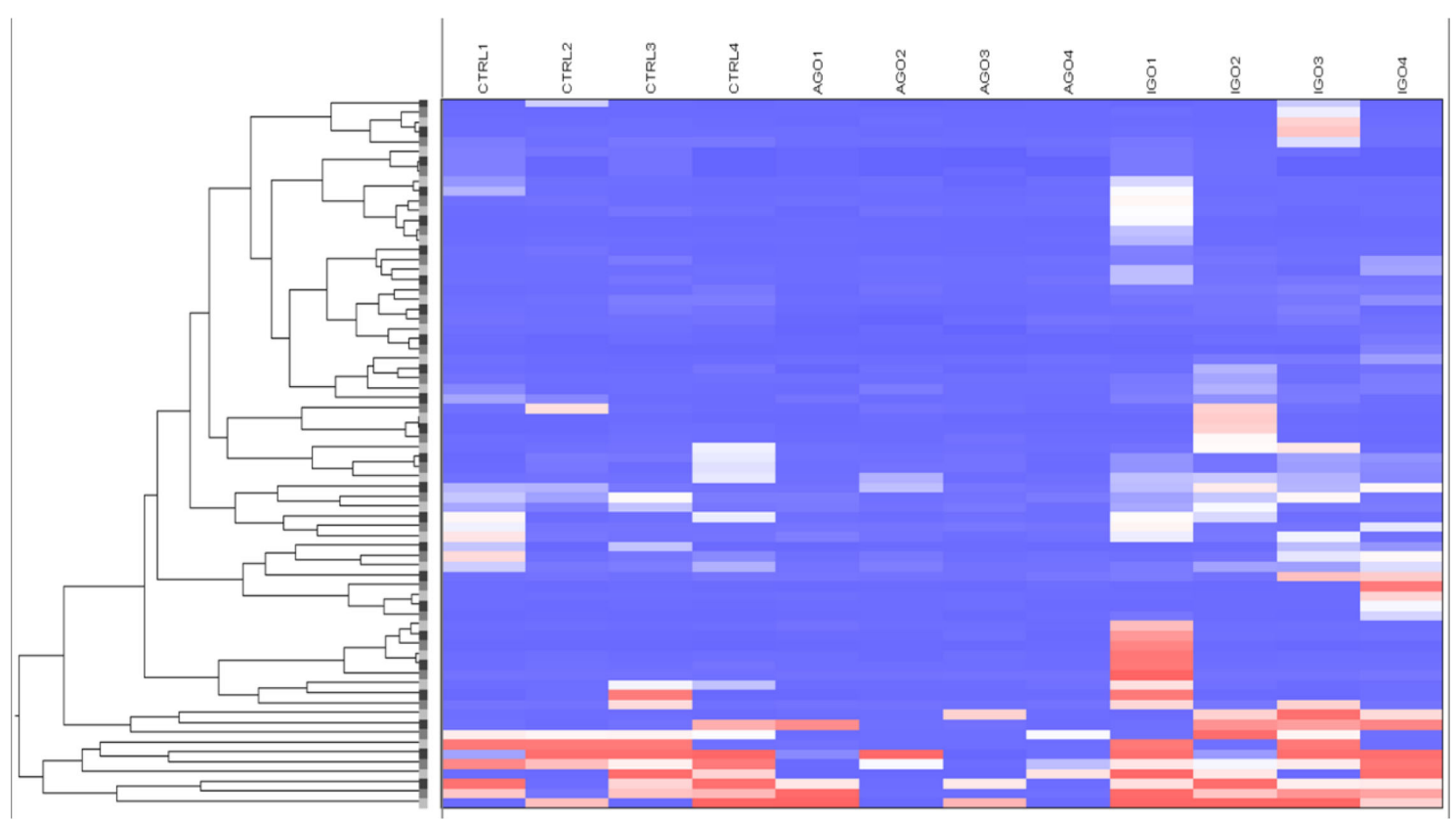

FIGURE 5 | Hypomethylated genes in orbital fibroblasts from active GO in comparison to orbital fibroblasts from inactive GO and healthy controls with a fold difference $\geq 2$. DNA methylation in active $G O$ orbital fibroblasts $(n=4)$ were compared with inactive $G O$ orbital fibroblasts $(n=4)$. Global DNA methylation was measured using the Illumina Infinium Human Methylation 450K beadchip on bisulphite-treated DNA and analyzed by GenomeStudio methylation analysis package. Hypomethylated genes with differences in DNA methylation level of at least 2-fold in active GO orbital fibroblasts were clustered as shown in the heatmap. 
A
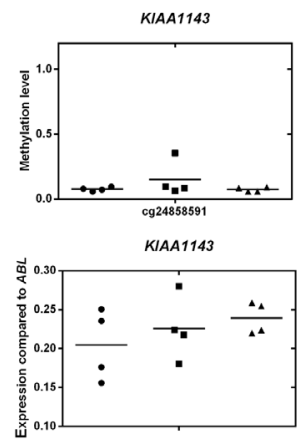

KIAA1143

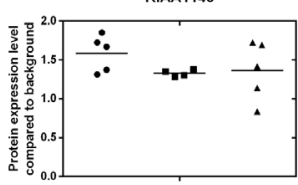

B
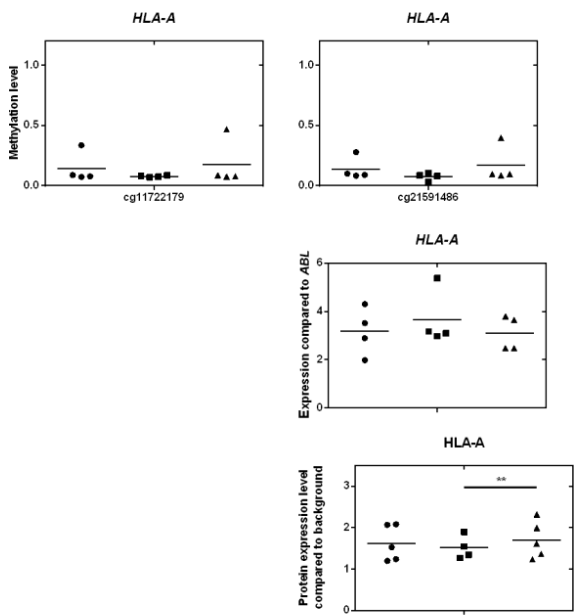

ANKRD11

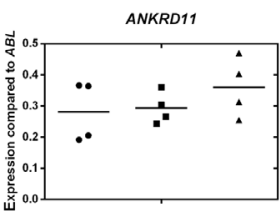

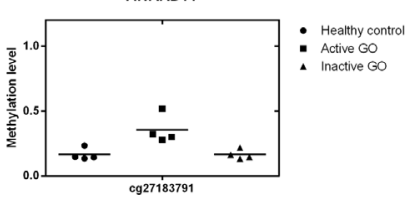

PPP1R7

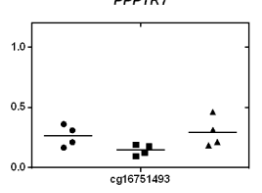

PPP1RT

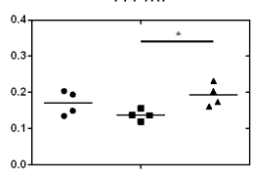

PPP1R7

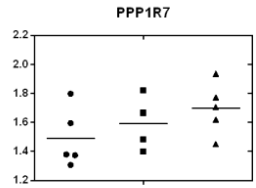

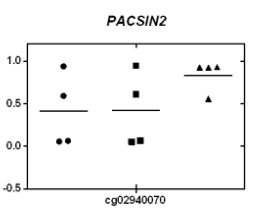

PACSIN2

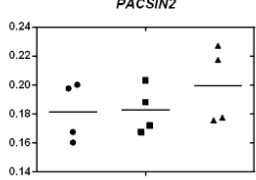

PACSIN2

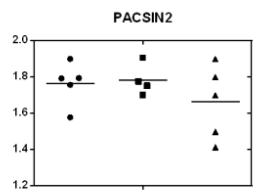

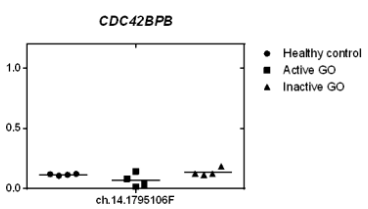
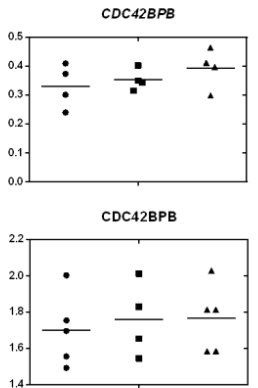

FIGURE 6 | Comparison of DNA methylation, mRNA expression and proteomic data. (A) Comparison of hypermethylated genes, mRNA expression and proteomic data. Gene expression was determined by real-time quantitative (RQ)-PCR and normalized to the control gene $A B L$. Data from mRNA expression was analyzed using ANOVA and subsequently analyzed with the Mann Whitney $U$ test. Individual symbols represent orbital fibroblast cultures from individual patients. Horizontal bar depicts the median. (B) Comparison of hypomethylated genes, mRNA expression and proteomic data. Gene expression was determined by real-time quantitative (RQ)-PCR and normalized to the control gene ABL. Data from mRNA expression was analyzed using ANOVA and subsequently analyzed with the Mann Whitney $U$ test. Individual symbols represent orbital fibroblast cultures from individual patients. Horizontal bar depicts the median.

detected by one probe in the gene body), SIM2 (detected with 2 different probes located in the gene body: 2.19-fold differences at cg15316660 and 2.03-fold differences at cg23286646 in the gene body), AIRE (detected with 2 different probes: 2.35-fold difference at cg27251412 and 2.34-fold difference at cg09510531 200 nucleotides upstream of the transcriptional start site; TSS200) and HLA-A (detected with 2 different probes: 2.27-fold difference at cg11722179 and 2.22-fold difference at $\operatorname{cg} 21591486$ in the gene body) (Figure 6B and Supplementary Figure 4).

To investigate the effects of differential methylation at the TSS200 in AIRE and gene-body in HLA-A, mRNA expression levels were determined by RQ-PCR. AIRE gene expression was not detectable by RQ-PCR in any of the orbital fibroblasts (data not shown), while $H L A-A$ was not differentially expressed at the mRNA level between fibroblasts from active $\mathrm{GO}$ and inactive $\mathrm{GO}$ (Figure 6B). AIRE protein expression was not detected by the current proteomics approach (data not shown), while HLA-A protein expression was significantly down-regulated in active GO orbital fibroblasts (Figure 6B).

\section{Integrative Analysis of Proteomics and Gene Methylation in Orbital Fibroblasts From Active GO Patients}

Upon integration of the DNA hypermethylation data with the proteome data, KIAA and the ANKRD gene family emerged from 

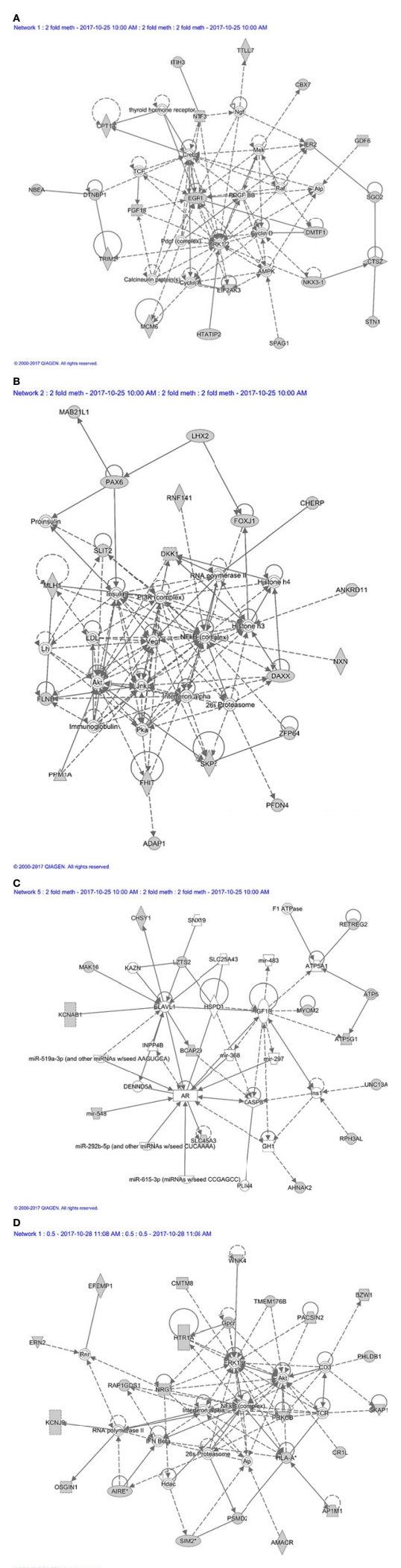

FIGURE 7 | Continued

FIGURE 7 | Methylation based network analysis. (A) Network 1 derived from hypermethylated genes in orbital fibroblasts from active GO: linked to neurological disease, organismal injury and abnormalities, and nervous system development and function Network analysis was further performed on these differentially hypermethylated genes (highlighted in grey) using Ingenuity (Qiagen) filtering only for those networks and pathways that are based on experimentally obtained information. (B) Network 2 derived from hypermethylated genes in orbital fibroblasts from active GO: linked to embryogenic development, nervous system development and function, and organ development. Network analysis was further performed on these differentially hypermethylated genes (highlighted in grey) using Ingenuity (Qiagen) filtering only for those networks and pathways that are based on experimentally obtained information. (C) Network 3 derived from hypermethylated genes in orbital fibroblasts from active GO: linked to cardiovascular system development and function, organismal development, and cellular assembly and organization. Network analysis was further performed on these differentially hypermethylated genes (highlighted in grey) using Ingenuity (Qiagen) filtering only for those networks and pathways that are based on experimentally obtained information. (D) Network 4 derived from hypomethylated genes in orbital fibroblasts from active GO: linked to cellular growth and proliferation, nervous system development and function, and cell-to-cell signaling and interaction. Network analysis was further performed on these differentially hypomethylated genes (highlighted in grey) using Ingenuity (Qiagen) filtering only for those networks and pathways that are based on experimentally obtained information.

both types of analyses and were therefore further examined by RQ-PCR. Although hypermethylation of KIAA1143 and $A N K R D 11$ genes was more than 2-fold, neither KIAA1143 nor ANKRD11 mRNA expression reached statistically significant difference in expression when comparing active and inactive GO orbital fibroblasts (Figure 6A). In addition, ANKRD11 protein was not detected by the current proteomics approach (data not shown). Neither the difference on gene expression data and proteome data reached statistical significance nor corresponded to the DNA methylation data.

Integration of the DNA hypermethylation data with the proteome data revealed overlap for PPP1R, PACSIN, and the CDC42 family, which were subsequently further validated by RQ-PCR. Although trends towards elevated mRNA expression for PACSIN2 and CDC42BPB were observed in inactive GO, no statistical significance existed among orbital fibroblast groups, while PPP1R7 mRNA expression was significantly $(\mathrm{p}<0.05)$ higher in inactive $\mathrm{GO}$ orbital fibroblasts than in active $\mathrm{GO}$ orbital fibroblasts $(\mathrm{P}<0.05)$ (Figure 6B). However, neither the mRNA expression data nor the proteome data corresponded to the DNA methylation data.

\section{Network Analysis From Methylated Genes in Orbital Fibroblasts From GO Patients}

Next, all the genes that displayed differential DNA methylation between orbital fibroblasts from active GO and inactive GO were fed into Ingenuity pathway analysis to identify potential critical molecular networks involved in GO pathogenesis. The top network with the highest score obtained for hypermethylated genes in active GO orbital fibroblasts genes included TSHR signaling, PDGF-BB signaling and the ERK1/2 signal transduction pathway, as depicted in network 1 (Figure 7A). Ingenuity linked this network mainly to neurological disease, organismal injury and abnormalities, and nervous system development and function. EGR1, one of the top 10 genes with the highest fold methylation difference, was also found in this network. The second network with the second highest 
score (designated as network 2) contained genes that were associated with the PI $3 \mathrm{~K}, \mathrm{NF}-\mathrm{\kappa B}$, JNK and Akt signaling pathways (Figure 7B). Ingenuity linked this network mainly to embryogenic development, nervous system development and function, and organ development. Clearly, these signaling cascades exert several important roles in immune activation as well as fibrosis $(27,44,50,51)$. In addition, Mir548F5 was found in another network (network 3) together with MYOM2 and RPH3AL and were connected to IGF-1R, androgen receptor and various noncoding RNAs (Figure 7C). Ingenuity linked this network mainly to cardiovascular system development and function, organismal development, and cellular assembly and organization. Moreover, LZTS2 and MYOM2 found in this network are among the top 10 genes with the highest fold difference in methylation status (Figure 7C).

For hypomethylated genes in active GO orbital fibroblasts, 6 of the top 10 genes with the highest fold difference were found in network 4, including ERN2, CMTM8, BZW1, PRKCB, PSMD2 and $A P 1 M 1$ (Figure 7D). Of the genes that were found hypomethylated in orbital fibroblasts from active GO, AIRE and SIM2 linked to network (network 4) that also contained NF- $\kappa \mathrm{B}, \mathrm{ERK} 1 / 2$ and Akt signaling pathways (Figure 7D). HLA$A$ and PSMD2 (proteasome 26S subunit, non-ATPase 2), that are associated with peptide degradation, antigen presentation and TCR signaling processes, also linked to network 4 (Figure 7D). Ingenuity associated network 4 mainly with cellular growth and proliferation, nervous system development and function, and cell-to-cell signaling and interaction.

TABLE 3 | Top 5 canonical pathways and diseases and bio-functions from the hypermethylated genes with the cut-off at more than 2-fold difference in the active $\mathrm{GO}$ orbital fibroblasts.

\section{Top Canonical Pathways}

\begin{tabular}{lcc}
\hline Name & p-value & Overlap \\
\hline Tyrosine Biosynthesis IV & 0.0145 & $33.3 \%$ \\
Phenylalanine Degradation I (Aerobic) & 0.0193 & $25.0 \%$ \\
Chondroitin and Dermatan Biosynthesis & 0.0289 & $16.7 \%$ \\
Glutamate Receptor Signaling & 0.0315 & $3.5 \%$ \\
NAD Biosynthesis from 2-amino-3- & 0.0336 & $14.3 \%$
\end{tabular}

carboxymuconate Semialdehyde

Top Diseases and Bio Functions

Diseases and Disorders

\begin{tabular}{|c|c|c|}
\hline Name & $\mathrm{p}$-value & \#Molecules \\
\hline Cancer & $1 \times 10^{-6}-0.0145$ & 95 \\
\hline Gastrointestinal Disease & $1 \times 10^{-6}-0.0145$ & 90 \\
\hline Organismal Injury and Abnormalities & $1 \times 10^{-6}-0.0145$ & 97 \\
\hline Developmental Disorder & $2.22 \times 10^{-5}-0.0145$ & 26 \\
\hline Ophthalmic Disease & $2.22 \times 10^{-5}-0.0145$ & 9 \\
\hline \multicolumn{3}{|l|}{ Molecular and Cellular Functions } \\
\hline Name & p-value & \#Molecules \\
\hline Gene Expression & $7.0 \times 10^{-5}-0.00209$ & 30 \\
\hline Cellular Development & $7.0 \times 10^{-5}-0.0145$ & 28 \\
\hline Cellular Growth and Proliferation & $7.0 \times 10^{-5}-0.0145$ & 25 \\
\hline Cell Cycle & $4.85 \times 10^{-4}-0.0145$ & 18 \\
\hline Cell Morphology & $4.85 \times 10^{-4}-0.0145$ & 14 \\
\hline
\end{tabular}

\section{Pathway and Functional Analysis From Methylated Genes in the Orbital Fibroblasts From GO Patients}

The top 5 canonical pathways obtained from genes hypermethylated in orbital fibroblasts from active GO are shown in Table 3, while for genes hypomethylated in orbital fibroblasts form active GO the top 5 canonical pathways are given in Table 4 . When all the functions from genes hypermethylated and hypomethylated in active GO (Tables 3 and 4) were integrated, overlapping bio-functions and diseases became apparent. The top disease/disorder identified to be shared between the hypo- and hypermethylated genes was organismal injury and abnormalities, containing ninety-seven hypermethylated genes $\left(\mathrm{p}\right.$-value $\left.=1 \times 10^{-6}-0.0145\right)$ and sixty-two hypomethylated genes $\left(\mathrm{p}\right.$-value $\left.=9.88 \times 10^{-5}-0.0498\right)$. For the molecular and cellular functions, cellular development and cellular growth and proliferation were among the top molecular and cellular functions that were shared between the hypo- and hypermethylated genes. Cellular development linked to 28 hypermethylated genes ( $\mathrm{p}$-value $=7.02 \times 10^{-5}-0.0145$ ) (Table 3) and nineteen hypomethylated genes ( $\mathrm{p}$-value = 0.00132 - 0.0469) (Table 4), while cellular growth and proliferation linked to twenty-five hypermethylated genes ( $\mathrm{p}$ value $\left.=7.02 \times 10^{-5}-0.0145\right)($ Table 3$)$ and seventeen hypomethylated genes $\left(\mathrm{p}\right.$-value $\left.=1.32 \times 10^{-4}-0.0498\right)($ Table 4$)$.

TABLE 4 | Top 5 canonical pathways and diseases and bio-functions from the hypomethylated genes with the cut-off at more than 2-fold difference in the active GO orbital fibroblasts.

Top Canonical Pathways

\begin{tabular}{lcc}
\hline Name & p-value & Overlap \\
\hline $\begin{array}{lcc}\text { Lipoate Salvage and Modification } \\
\text { Lipoate Biosynthesis and Incorporation }\end{array}$ & 0.003 & $100.0 \%$ \\
II & 0.00598 & $50.0 \%$ \\
Dopamine-DARPP32 Feedback in cAMP & 0.0132 & $1.8 \%$ \\
Signaling & & \\
Nur77 Signaling in T Lymphocytes & 0.0136 & $3.4 \%$ \\
Wnt/Ca2+ pathway & 0.0154 & $3.2 \%$ \\
$\begin{array}{l}\text { Top Diseases and Bio Functions } \\
\text { Diseases and Disorders }\end{array}$ & & \\
\hline
\end{tabular}

\begin{tabular}{lcc}
\hline Name & p-value & \#Molecules \\
\hline Cancer & $9.88 \times 10^{-5}-0.0498$ & 61 \\
Organismal Injury and Abnormalities & $9.88 \times 10^{-5}-0.0498$ & 62 \\
Dermatological Diseases and & $4.73 \times 10^{-4}-0.0496$ & 43 \\
Conditions & & \\
Gastrointestinal Disease & $0.00106-0.044$ & 55 \\
Metabolic Disease & $0.00172-0.0498$ & 8 \\
Molecular and Cellular Functions & &
\end{tabular}

\begin{tabular}{lcc}
\hline Name & p-value & \#Molecules \\
\hline Cellular Growth and Proliferation & $1.32 \times 10^{-4}-0.0498$ & 17 \\
Cellular Movement & $0.00117-0.0498$ & 12 \\
Cell-To-Cell Signaling and Interaction & $0.00132-0.0498$ & 13 \\
Cellular Development & $0.00132-0.0469$ & 19 \\
Drug Metabolism & $0.00132-0.0452$ & 4
\end{tabular}




\section{DISCUSSION}

Disease activity and characteristics of GO alter with disease progression. Early active GO is characterized by active inflammation that progresses into a late inactive phase without apparent inflammation but characterized by extensive orbital tissue remodeling (increased adipose tissue formation, excessive hyaluronan deposition and fibrosis). Orbital fibroblasts represent the main effector cells in GO and contribute to both the early active and late inactive phases of disease (8). Here, we performed extensive proteomics and global DNA methylation analysis of orbital fibroblasts from active and inactive GO as well as control individuals. Our data clearly demonstrate distinctive proteome and DNA methylation profiles between orbital fibroblasts from patients with active and inactive GO. These profiles can be linked to pathologically relevant molecular networks specifically associated with active/inactive disease stage, including inflammation, cellular development, growth, proliferation and tissue remodeling. Therefore, this data clearly illustrates that with GO disease progression orbital fibroblasts exhibit specific characteristics linked to disease stage specific pathology, and that epigenetic regulation is involved in controlling this.

Orbital fibroblasts from active GO displayed overexpression of proteins typically involved in inflammation, cellular proliferation, hyaluronan synthesis and adipogenesis (Figure 1C). In contrast, various proteins linked to ECM biology and fibrotic disease were overexpressed in orbital fibroblasts from inactive GO (Figure 1B). These findings corroborated with the different types of networks identified, which included cellular development and connective tissue disorders, DNA replication, recombination and repair and cellular assembly and organization (Figure 2). Although our current protein findings fit the pathophysiological model of GO, further studies to unravel the exact function of these proteins in orbital fibroblasts as well as their contribution to the different stages of GO are required.

To our knowledge, our study is the first that explored DNA methylation in orbital fibroblasts from GO patients. Comparison of DNA methylation with stringent analysis using FDR between healthy controls and all the GO orbital fibroblasts included in our study resulted in a significant difference in methylation only for SLC39A8 (hypermethylation in 3'UTR region in case of the GO orbital fibroblasts; Figure 3). SLC39A8 is a member of the major zinc transporter SLC39 (ZIP) family, and cellular zinc import by SLC39A8 is crucial in the control of immune activation and function $(52,53)$. SLC39A8 methylation status did not correlate with mRNA expression, while SLC39A8 protein was not detected at all. However, the SLC93A8 hypermethylation in GO orbital fibroblasts located to the 3'UTR region, a region in which hypermethylation does not necessarily relate to transcriptional repression as commonly reported in promoter regions (54-56). We can, however, not exclude that SLC39A8 expression is also controlled by other regulatory mechanism such as small non-coding RNAs. SLC39A8 is also thought to be the primary transporter of the toxic cation cadmium, which is found in cigarette smoke. In this study we did not detect SLC93A8 protein, which might be related to the sensitivity of the technique we applied. Yet, we propose that additional studies to understand the role of the SLC39A8 and other SLC39 family of solute carriers in the pathogenesis of GO are potentially of great interest considering that smoking is a major environmental risk factor for GO (57).

Additional analysis of global DNA methylation using a 2-fold difference cut-off was conducted with the intend to lower the stringency from FDR analysis. A drawback of this approach is however that individual outliers have a relatively large effect on the final outcome, which either may mask potential important

\section{Orbital fibroblasts effectors characteristics}

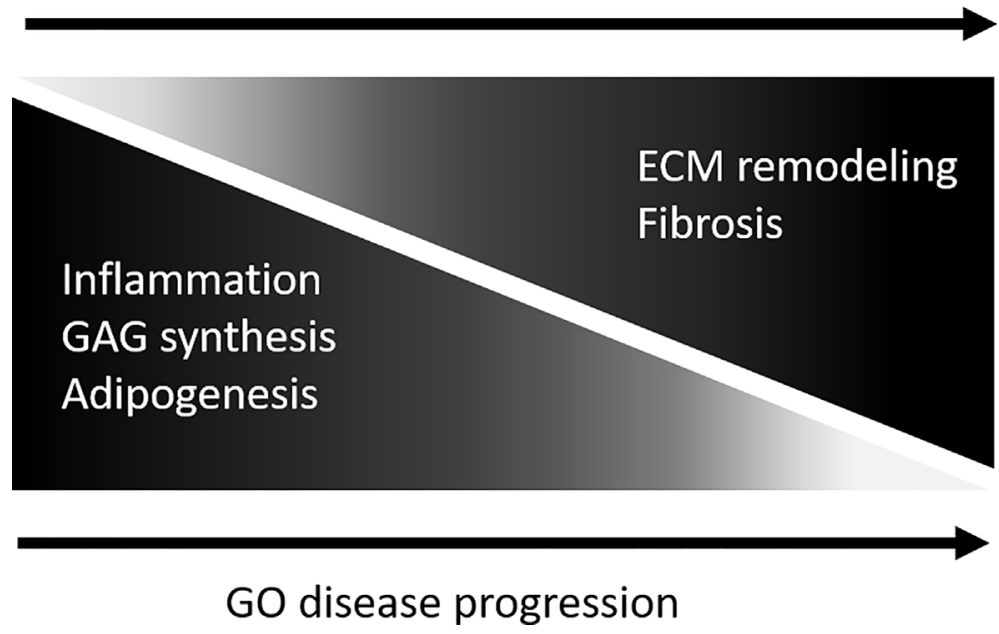

FIGURE 8 | Model depicting orbital fibroblast effector characteristics upon GO disease progression. During active disease orbital fibroblasts are skewed towards a functional phenotype involved in in inflammation, glycosaminoglycan synthesis and adipogenesis. With disease progression the orbital fibroblasts undergo a switch from this "inflammatory/pro-adipogenic primed" effector cell towards a "remodelling/pro-fibrotic" type of effector cell. 
differences in methylation or identify false positive methylation differences, especially with the small groups ( $n=4$ per group) used in this study. Nonetheless, the overall DNA methylation patterns we observed suggest that orbital fibroblasts from inactive GO are more comparable to control orbital fibroblasts than to orbital fibroblasts from active GO (Figures 4 and 5). The global DNA methylation patterns and associated networks we found corroborate with the networks generated from the proteomics analysis, including NF- $\kappa \mathrm{B}$, Akt and IFN $\alpha$ (Figures 2 and 7), as well as previous reports that linked these pathways to GO pathogenesis (58-60). Other genes hypermethylated in inactive GO orbital fibroblasts also linked to other pathogenic pathways previously reported in GO, including PDGF (44), thyroid hormone receptor (61), NGF (62), AMPK (63) and ERK1/2 signaling pathways $(64,65)$ (Figure 7$)$. In orbital fibroblasts from active GO hypermethylated genes clearly linked to inflammation, while hypomethylated genes linked to adipogenesis and autoimmune-related genes. This is in line with the association to inflammation and adipogenesis that we observed for the proteome of active GO orbital fibroblasts.

Genes hypomethylated in active GO orbital fibroblasts included $A I R E$ and HLA-A (Figure 6B and Supplementary Figure 4). AIRE controls tissue specific antigen expression by medullary thymic epithelial cells to control thymic T-cell selection, and AIRE deficiency is associated with autoimmune disease $(66,67)$. CpG methylation in the promoter of the AIRE gene has previously been reported to control its tissue-specific expression pattern (68). Although hypomethylation of AIRE promoter was found in orbital fibroblasts from active GO (Supplementary Figure 4), AIRE expression was undetectable at mRNA and protein level (data not shown). Several studies showed AIRE expression in fibrocytes that typically infiltrate the orbital tissue form GO patients $(69,70)$. Potentially, fibrocyte numbers in our heterogeneous orbital fibroblast populations were low, which did however still allow detection of differences in AIRE methylation but not in AIRE mRNA or protein. HLA-A hypomethylation was detected in the gene body in orbital fibroblasts from active GO (Figure 6B). While $H L A-A$ mRNA expression level did not differ between active and inactive GO, HLA-A protein expression was significantly down-regulated in active GO orbital fibroblasts (Figure 6B). Decreased HLA-A protein expression as observed in the orbital fibroblasts from active GO might regulate antigen presentation by these cells.

Fibroblasts isolated from fibrotic tissue display phenotypes that remain stable in in vitro culture for prolonged periods of time (71, 72). This allows investigation of epigenetic alterations and regulation, including histone modification, DNA methylation and non-coding RNA $(71,73)$. In general, we observed a poor correlation between protein expression, DNA methylation and mRNA expression. Poor correlations between DNA promotor methylation level and gene expression, as well as both positive and negative correlations between DNA gene body methylation and gene expression, have been reported (74-76). Our study thus clearly indicates that the proteome alterations we observed in orbital fibroblasts in relation to the specific GO disease stage are controlled by regulatory layers additional to DNA methylation (e.g. histone modifications and small regulatory RNA molecules) that remain so-far hardly studied in GO. For example, several microRNAs, including miR-322, miR-508-3p, miR-9 and miR-16 have been described to target NFKB1 mRNA (77-80). miR-16 was previously found to be upregulated in orbital tissue from inactive GO patients and might thus be involved in downregulating NFKB1 and resolving inflammation that occurs during this disease stage (81). Altogether, the current data support the role of NF- $\mathrm{BB}$ signaling in regulating inflammation in GO orbital fibroblasts. Moreover, the data point towards existence of a complex epigenetic regulation machinery that controls NFKB1 expression and activity with GO disease progression.

There are several limitations associated with our study. First, the sample size is small, and it cannot be excluded that the extended orbital fibroblast isolation protocol and culture procedure altered the in vivo phenotypic/effector cell character of the orbital fibroblasts, although long term (epigenetic)stability of fibroblasts in culture is previously described $(71,72)$. Second, orbital fibroblasts are heterogeneous (8). Therefore, use of purified fibroblast subpopulations on the basis of cell surface marker expression, for instance Thy-1, CD34 and TSHR, could generate more in-depth insight into epigenetic regulation and fibroblast-subtype specific proteomes in GO. Despite these limitations, our proteomic and DNA methylation analysis identified known as well as novel molecules and molecular networks in relation to the pathogenesis of GO. In addition, both the proteomics and DNA methylation support that, with GO disease progression, orbital fibroblasts undergo a switch from an "inflammatory/pro-adipogenic primed" effector cell to a "remodeling/pro-fibrotic" type of effector cell, as depicted in Figure 8. We propose that detailed molecular understanding of this "inflammatory/pro-angiogenic-toremodeling/pro-fibrotic switch" should be an active field of future research as it can contribute to improvement of treatment protocols.

\section{DATA AVAILABILITY STATEMENT}

The mass spectrometry proteomics data have been deposited to the ProteomeXchange Consortium via the PRIDE partner repository with the dataset identifier PXD022257.

\section{ETHICS STATEMENT}

The studies involving human participants were reviewed and approved by protocol ID-2007-01. The patients/participants provided their written informed consent to participate in this study.

\section{AUTHOR CONTRIBUTIONS}

SV designed research, performed research, analyzed and interpreted data, wrote the paper. PS performed research, analyzed data, wrote the paper. TPi designed research, analyzed data, contributed analytic tools, prepared manuscript. PS analyzed data, contributed analytic tools. DP contributed patient materials. VD, $\mathrm{PH}, \mathrm{NH}$, and 
TPa analyzed data, prepared manuscript. WD designed research, analyzed and interpreted data, prepared manuscript. All authors contributed to the article and approved the submitted version.

\section{FUNDING}

This research was funded by the TSRI Fund (CU_FRB640001_ 01_23_1), Ratchadapisek Sompoch Endowment Fund (2017), Chulalongkorn University (760001-HR), Asia Research Center, Chulalongkorn University (007/2560) and Chulalongkorn University Office of International Affairs Scholarship for Shortterm Research (3/2561).

\section{SUPPLEMENTARY MATERIAL}

The Supplementary Material for this article can be found online at: https://www.frontiersin.org/articles/10.3389/fendo.2020. 619989/full\#supplementary-material

\section{REFERENCES}

1. Kendall RT, Feghali-Bostwick CA. Fibroblasts in fibrosis: novel roles and mediators. Front Pharmacol (2014) 5:123.

2. Reilkoff RA, Bucala R, Herzog EL. Fibrocytes: emerging effector cells in chronic inflammation. Nat Rev Immunol (2011) 11(6):427-35.

3. Kis K, Liu X, Hagood JS. Myofibroblast differentiation and survival in fibrotic disease. Expert Rev Mol Med (2011) 13:e27.

4. Korfei M, Skwarna S, Henneke I, MacKenzie B, Klymenko O, Saito S, et al. Aberrant expression and activity of histone deacetylases in sporadic idiopathic pulmonary fibrosis. Thorax (2015) 70(11):1022-32.

5. Wynn TA, Ramalingam TR. Mechanisms of fibrosis: therapeutic translation for fibrotic disease. Nat Med (2012) 18(7):1028-40.

6. Darby IA, Zakuan N, Billet F, Desmouliere A. The myofibroblast, a key cell in normal and pathological tissue repair. Cell Mol Life Sci (2016) 73 (6):1145-57.

7. Bahn RS. Graves' ophthalmopathy. N Engl J Med (2010) 362(8):726-38.

8. Dik WA, Virakul S, van Steensel L. Current perspectives on the role of orbital fibroblasts in the pathogenesis of Graves' ophthalmopathy. Exp Eye Res (2016) 142:83-91.

9. Matheis N, Lantz M, Grus FH, Ponto KA, Wolters D, Brorson H, et al. Proteomics of Orbital Tissue in Thyroid-Associated Orbitopathy. J Clin Endocrinol Metab (2015) 100(12):E1523-30.

10. Cheng KC, Huang HH, Hung CT, Chen CC, Wu WC, Suen JL, et al. Proteomic analysis of the differences in orbital protein expression in thyroid orbitopathy. Graefes Arch Clin Exp Ophthalmol (2013) 251(12):2777-87.

11. Hwang CJ, Afifiyan N, Sand D, Naik V, Said J, Pollock SJ, et al. Orbital fibroblasts from patients with thyroid-associated ophthalmopathy overexpress CD40: CD154 hyperinduces IL-6, IL-8, and MCP-1. Invest Ophthalmol Vis Sci (2009) 50(5):2262-8.

12. Pritchard J, Han R, Horst N, Cruikshank WW, Smith TJ. Immunoglobulin activation of $\mathrm{T}$ cell chemoattractant expression in fibroblasts from patients with Graves' disease is mediated through the insulin-like growth factor I receptor pathway. J Immunol (2003) 170(12):6348-54.

13. Khoo TK, Coenen MJ, Schiefer AR, Kumar S, Bahn RS. Evidence for enhanced Thy-1 (CD90) expression in orbital fibroblasts of patients with Graves' ophthalmopathy. Thyroid (2008) 18(12):1291-6.

14. Tang F, Chen X, Mao Y, Wan S, Ai S, Yang H, et al. Orbital fibroblasts of Graves' orbitopathy stimulated with proinflammatory cytokines promote B cell survival by secreting BAFF. Mol Cell Endocrinol (2017) 446:1-11.

15. Virakul S, Heutz JW, Dalm VA, Peeters RP, Paridaens D, van den Bosch WA, et al. Basic FGF and PDGF-BB synergistically stimulate hyaluronan and IL-6 production by orbital fibroblasts. Mol Cell Endocrinol (2016) 433:94-104.
Supplementary Figure 1 | Comparison of GNAS DNA methylation and protein expression data.

Supplementary Figure 2 | Expression of DNMT and TET genes were determined by real-time quantitative (RQ)-PCR and normalized to the control gene $A B L$. Individual symbols represent orbital fibroblast cultures from individual patients. Horizontal bar depicts the median.

Supplementary Figure 3 | Methylation level of hypermethylated genes in orbital fibroblasts from active GO. Methylation level ranges from 0 (unmethylated) to 1 (fully methylated). Genes that were detected with the highest fold difference between active and inactive GO orbital fibroblasts, WDR8, and genes that were detected by more than one probe, Mir548F5 and MAB21L1, are shown in this figure. Individual symbols represent orbital fibroblast cultures from individual patients. Horizontal bar depicts the median.

Supplementary Figure 4 | Methylation level of hypomethylated genes in orbital fibroblasts from active GO. Methylation level ranges from 0 (unmethylated) to 1 (fully methylated). Genes that were detected with the highest fold difference between active and inactive GO orbital fibroblasts, RNF168, and genes that were detected by more than one probe, AIRE and SIM2, are shown in this figure. Individual symbols represent orbital fibroblast cultures from individual patients. Horizontal bar depicts the median.

16. Lee WM, Paik JS, Cho WK, Oh EH, Lee SB, Yang SW. Rapamycin enhances TNF-alpha-induced secretion of IL- 6 and IL-8 through suppressing PDCD4 degradation in orbital fibroblasts. Curr Eye Res (2013) 38(6):699-706.

17. Mimura LY, Villares SM, Monteiro ML, Guazzelli IC, Bloise W. Peroxisome proliferator-activated receptor-gamma gene expression in orbital adipose/ connective tissues is increased during the active stage of Graves' ophthalmopathy. Thyroid (2003) 13(9):845-50.

18. Wakelkamp IM, Bakker O, Baldeschi L, Wiersinga WM, Prummel MF. TSH$\mathrm{R}$ expression and cytokine profile in orbital tissue of active vs. inactive Graves' ophthalmopathy patients. Clin Endocrinol (Oxf) (2003) 58(3):280-7.

19. Altorok N, Tsou PS, Coit P, Khanna D, Sawalha AH. Genome-wide DNA methylation analysis in dermal fibroblasts from patients with diffuse and limited systemic sclerosis reveals common and subset-specific DNA methylation aberrancies. Ann Rheum Dis (2015) 74(8):1612-20.

20. Huang SK, Scruggs AM, McEachin RC, White ES, Peters-Golden M. Lung fibroblasts from patients with idiopathic pulmonary fibrosis exhibit genomewide differences in DNA methylation compared to fibroblasts from nonfibrotic lung. PloS One (2014) 9(9):e107055.

21. Hemmatazad H, Rodrigues HM, Maurer B, Brentano F, Pileckyte M, Distler $\mathrm{JH}$, et al. Histone deacetylase 7, a potential target for the antifibrotic treatment of systemic sclerosis. Arthritis Rheum (2009) 60(5):1519-29.

22. Bagnato G, Roberts WN, Roman J, Gangemi S. A systematic review of overlapping microRNA patterns in systemic sclerosis and idiopathic pulmonary fibrosis. Eur Respir Rev (2017) 26(144).

23. Khong JJ, Wang LY, Smyth GK, McNab AA, Hardy TG, Selva D, et al. Differential Gene Expression Profiling of Orbital Adipose Tissue in Thyroid Orbitopathy. Invest Ophthalmol Vis Sci (2015) 56(11):6438-47.

24. Bartalena L, Baldeschi L, Dickinson AJ, Eckstein A, Kendall-Taylor P, Marcocci C, et al. Consensus statement of the European group on Graves' orbitopathy (EUGOGO) on management of Graves' orbitopathy. Thyroid (2008) 18(3):333-46.

25. van Steensel L, Paridaens D, Schrijver B, Dingjan GM, van Daele PL, van Hagen PM, et al. Imatinib mesylate and AMN107 inhibit PDGF-signaling in orbital fibroblasts: a potential treatment for Graves' ophthalmopathy. Invest Ophthalmol Vis Sci (2009) 50(7):3091-8.

26. Concetti J, Wilson CL. NFKB1 and Cancer: Friend or Foe? Cells (2018) 7(9).

27. Mussbacher M, Salzmann M, Brostjan C, Hoesel B, Schoergenhofer C, Datler $\mathrm{H}$, et al. Cell Type-Specific Roles of NF-kappaB Linking Inflammation and Thrombosis. Front Immunol (2019) 10:85.

28. van Steensel L, Paridaens D, Dingjan GM, van Daele PL, van Hagen PM, Kuijpers RW, et al. Platelet-derived growth factor-BB: a stimulus for cytokine production by orbital fibroblasts in Graves' ophthalmopathy. Invest Ophthalmol Vis Sci (2010) 51(2):1002-7. 
29. Oakley F, Mann J, Nailard S, Smart DE, Mungalsingh N, Constandinou C, et al. Nuclear factor-kappaB1 (p50) limits the inflammatory and fibrogenic responses to chronic injury. Am J Pathol (2005) 166(3):695-708.

30. Kahaly G, Forster G, Hansen C. Glycosaminoglycans in thyroid eye disease. Thyroid (1998) 8(5):429-32.

31. Smith TJ, Tsai CC, Shih MJ, Tsui S, Chen B, Han R, et al. Unique attributes of orbital fibroblasts and global alterations in IGF-1 receptor signaling could explain thyroid-associated ophthalmopathy. Thyroid (2008) 18(9):983-8.

32. Vigetti D, Viola M, Karousou E, De Luca G, Passi A. Metabolic control of hyaluronan synthases. Matrix Biol (2014) 35:8-13.

33. Roach W, Plomann M. PACSIN3 overexpression increases adipocyte glucose transport through GLUT1. Biochem Biophys Res Commun (2007) 355(3):745-50

34. Aoh QL, Graves LM, Duncan MC. Glucose regulates clathrin adaptors at the trans-Golgi network and endosomes. Mol Biol Cell (2011) 22(19):3671-83.

35. Meyer zu Horste M, Stroher E, Berchner-Pfannschmidt U, Schmitz-Spanke S, Pink M, Gothert JR, et al. A novel mechanism involved in the pathogenesis of Graves ophthalmopathy (GO): clathrin is a possible targeting molecule for inhibiting local immune response in the orbit. J Clin Endocrinol Metab (2011) 96(11):E1727-36.

36. Brinckmann J, Hunzelmann N, Kahle B, Rohwedel J, Kramer J, Gibson MA, et al. Enhanced fibrillin-2 expression is a general feature of wound healing and sclerosis: potential alteration of cell attachment and storage of TGF-beta. Lab Invest (2010) 90(5):739-52.

37. Chen $\mathrm{W}$, Zhao W, Yang A, Xu A, Wang H, Cong M, et al. Integrated analysis of microRNA and gene expression profiles reveals a functional regulatory module associated with liver fibrosis. Gene (2017) 636:87-95.

38. Specks U, Nerlich A, Colby TV, Wiest I, Timpl R. Increased expression of type VI collagen in lung fibrosis. Am J Respir Crit Care Med (1995) 151 (6):1956-64.

39. Theocharidis G, Drymoussi Z, Kao AP, Barber AH, Lee DA, Braun KM, et al. Type VI Collagen Regulates Dermal Matrix Assembly and Fibroblast Motility. J Invest Dermatol (2016) 136(1):74-83.

40. Fleischmajer R, Jacobs L, Schwartz E, Sakai LY. Extracellular microfibrils are increased in localized and systemic scleroderma skin. Lab Invest (1991) 64 (6):791-8.

41. Specks U, Mayer U, Nischt R, Spissinger T, Mann K, Timpl R, et al. Structure of recombinant $\mathrm{N}$-terminal globule of type VI collagen alpha 3 chain and its binding to heparin and hyaluronan. EMBO J (1992) 11(12):4281-90.

42. Somasundaram R, Schuppan D. Type I, II, III, IV, V, and VI collagens serve as extracellular ligands for the isoforms of platelet-derived growth factor (AA, BB, and AB). J Biol Chem (1996) 271(43):26884-91.

43. Schuppan D, Schmid M, Somasundaram R, Ackermann R, Ruehl M, Nakamura T, et al. Collagens in the liver extracellular matrix bind hepatocyte growth factor. Gastroenterology (1998) 114(1):139-52.

44. Virakul S, van Steensel L, Dalm VA, Paridaens D, van Hagen PM, Dik WA. Platelet-derived growth factor: a key factor in the pathogenesis of graves' ophthalmopathy and potential target for treatment. Eur Thyroid J (2014) 3 (4):217-26

45. Yamane K, Mazaki T, Shiozaki Y, Yoshida A, Shinohara K, Nakamura M, et al. Collagen-Binding Hepatocyte Growth Factor (HGF) alone or with a Gelatinfurfurylamine Hydrogel Enhances Functional Recovery in Mice after Spinal Cord Injury. Sci Rep (2018) 8(1):917.

46. Nowak M, Sieminska L, Karpe J, Marek B, Kos-Kudla B, Kajdaniuk D. Serum concentrations of HGF and IL-8 in patients with active Graves' orbitopathy before and after methylprednisolone therapy. J Endocrinol Invest (2016) 39 (1):63-72.

47. Virakul S, Dalm VA, Paridaens D, van den Bosch WA, Mulder MT, Hirankarn N, et al. Platelet-Derived Growth Factor-BB Enhances Adipogenesis in Orbital Fibroblasts. Invest Ophthalmol Vis Sci (2015) 56(9):5457-64.

48. Rasmussen KK, Falkesgaard MH, Winther M, Roed NK, Quistgaard CL, Teisen MN, et al. NCAM2 Fibronectin type-III domains form a rigid structure that binds and activates the Fibroblast Growth Factor Receptor. Sci Rep (2018) 8(1):8957.

49. Schrijver B, Kooiman MA, Kasteleijn E, van Holten-Neelen C, Virakul S, Paridaens D, et al. Basic Fibroblast Growth Factor Induces Adipogenesis in Orbital Fibroblasts: Implications for the Pathogenesis of Graves' Orbitopathy. Thyroid (2019) 29(3):395-404.
50. Foglia B, Cannito S, Bocca C, Parola M, Novo E. ERK Pathway in Activated, Myofibroblast-Like, Hepatic Stellate Cells: A Critical Signaling Crossroad Sustaining Liver Fibrosis. Int J Mol Sci (2019) 20(11).

51. Fruman DA, Chiu H, Hopkins BD, Bagrodia S, Cantley LC, Abraham RT. The PI3K Pathway in Human Disease. Cell (2017) 170(4):605-35.

52. Fraker PJ, King LE. Reprogramming of the immune system during zinc deficiency. Annu Rev Nutr (2004) 24:277-98.

53. Liu MJ, Bao S, Galvez-Peralta M, Pyle CJ, Rudawsky AC, Pavlovicz RE, et al. ZIP8 regulates host defense through zinc-mediated inhibition of NF-kappaB. Cell Rep (2013) 3(2):386-400.

54. Malumbres M, Perez de Castro I, Santos J, Fernandez Piqueras J, Pellicer A. Hypermethylation of the cell cycle inhibitor p15INK4b 3'-untranslated region interferes with its transcriptional regulation in primary lymphomas. Oncogene (1999) 18(2):385-96.

55. Maussion G, Yang J, Suderman M, Diallo A, Nagy C, Arnovitz M, et al Functional DNA methylation in a transcript specific 3'UTR region of TrkB associates with suicide. Epigenetics (2014) 9(8):1061-70.

56. Shen Z, Zhu L, Zhang C, Cui X, Lu J. Overexpression of BHLHE41, correlated with DNA hypomethylation in 3'UTR region, promotes the growth of human clear cell renal cell carcinoma. Oncol Rep (2019) 41(4):2137-47.

57. Hegedius L, Brix TH, Vestergaard P. Relationship between cigarette smoking and Graves' ophthalmopathy. J Endocrinol Invest (2004) 27(3):265-71.

58. Romero-Kusabara IL, Filho JV, Scalissi NM, Melo KC, Demartino G, Longui CA, et al. Distinct inflammatory gene expression in extraocular muscle and fat from patients with Graves' orbitopathy. Eur J Endocrinol (2017) 176(4):481-8.

59. Li B, Smith TJ. PI3K/AKT pathway mediates induction of IL-1RA by TSH in fibrocytes: modulation by PTEN. J Clin Endocrinol Metab (2014) 99 (9):3363-72.

60. Gillespie EF, Raychaudhuri N, Papageorgiou KI, Atkins SJ, Lu Y, Charara LK, et al. Interleukin-6 production in CD40-engaged fibrocytes in thyroidassociated ophthalmopathy: involvement of Akt and NF-kappaB. Invest Ophthalmol Vis Sci (2012) 53(12):7746-53.

61. Iyer S, Bahn R. Immunopathogenesis of Graves' ophthalmopathy: the role of the TSH receptor. Best Pract Res Clin Endocrinol Metab (2012) 26(3):281-9.

62. Molnar I, Bokk A. Decreased nerve growth factor levels in hyperthyroid Graves' ophthalmopathy highlighting the role of neuroprotective factor in autoimmune thyroid diseases. Cytokine (2006) 35(3-4):109-14.

63. Li H, Yuan Y, Zhang Y, Zhang X, Gao L, Xu R. Icariin Inhibits AMPKDependent Autophagy and Adipogenesis in Adipocytes In vitro and in a Model of Graves' Orbitopathy In vivo. Front Physiol (2017) 8:45.

64. Tsui S, Naik V, Hoa N, Hwang CJ, Afifiyan NF, Sinha Hikim A, et al. Evidence for an association between thyroid-stimulating hormone and insulin-like growth factor 1 receptors: a tale of two antigens implicated in Graves' disease. J Immunol (2008) 181(6):4397-405.

65. Krieger CC, Perry JD, Morgan SJ, Kahaly GJ, Gershengorn MC. TSH/IGF-1 Receptor Cross-Talk Rapidly Activates Extracellular Signal-Regulated Kinases in Multiple Cell Types. Endocrinology (2017) 158(10):3676-83.

66. Perniola R. Twenty Years of AIRE. Front Immunol (2018) 9:98.

67. Gough SC, Simmonds MJ. The HLA Region and Autoimmune Disease: Associations and Mechanisms of Action. Curr Genomics (2007) 8 (7):453-65

68. Kont V, Murumagi A, Tykocinski LO, Kinkel SA, Webster KE, Kisand K, et al. DNA methylation signatures of the AIRE promoter in thymic epithelial cells, thymomas and normal tissues. Mol Immunol (2011) 49(3):518-26.

69. Fernando R, Lu Y, Atkins SJ, Mester T, Branham K, Smith TJ. Expression of thyrotropin receptor, thyroglobulin, sodium-iodide symporter, and thyroperoxidase by fibrocytes depends on AIRE. J Clin Endocrinol Metab (2014) 99(7):E1236-44.

70. Smith TJ. Potential Roles of CD34+ Fibrocytes Masquerading as Orbital Fibroblasts in Thyroid-Associated Ophthalmopathy. J Clin Endocrinol Metab (2019) 104(2):581-94.

71. O'Reilly S. Epigenetics in fibrosis. Mol Aspects Med (2017) 54:89-102.

72. Albrengues J, Bertero T, Grasset E, Bonan S, Maiel M, Bourget I, et al. Epigenetic switch drives the conversion of fibroblasts into proinvasive cancerassociated fibroblasts. Nat Commun (2015) 6:10204

73. Lund AH, van Lohuizen M. Epigenetics and cancer. Genes Dev (2004) 18 (19):2315-35 
74. Yang X, Han H, De Carvalho DD, Lay FD, Jones PA, Liang G. Gene body methylation can alter gene expression and is a therapeutic target in cancer. Cancer Cell (2014) 26(4):577-90.

75. Kulis M, Heath S, Bibikova M, Queiros AC, Navarro A, Clot G, et al. Epigenomic analysis detects widespread gene-body DNA hypomethylation in chronic lymphocytic leukemia. Nat Genet (2012) 44(11):1236-42.

76. Deaton AM, Webb S, Kerr AR, Illingworth RS, Guy J, Andrews R, et al. Cell type-specific DNA methylation at intragenic CpG islands in the immune system. Genome Res (2011) 21(7):1074-86.

77. Yang TQ, Lu XJ, Wu TF, Ding DD, Zhao ZH, Chen GL, et al. MicroRNA-16 inhibits glioma cell growth and invasion through suppression of BCL2 and the nuclear factor-kappaB1/MMP9 signaling pathway. Cancer Sci (2014) 105 (3):265-71.

78. Guo LM, Pu Y, Han Z, Liu T, Li YX, Liu M, et al. MicroRNA-9 inhibits ovarian cancer cell growth through regulation of NF-kappaB1. FEBS J (2009) 276(19):5537-46.

79. Huang T, Kang W, Zhang B, Wu F, Dong Y, Tong JH, et al. miR-508-3p concordantly silences NFKB1 and RELA to inactivate canonical NF-kappaB signaling in gastric carcinogenesis. Mol Cancer (2016) 15:9.
80. Zhang K, Song F, Lu X, Chen W, Huang C, Li L, et al. MicroRNA-322 inhibits inflammatory cytokine expression and promotes cell proliferation in LPSstimulated murine macrophages by targeting NF-kappaB1 (p50). Biosci Rep (2017) 37(1).

81. Jang SY, Chae MK, Lee JH, Lee EJ, Yoon JS. Role of miR-146a in the Regulation of Inflammation in an In Vitro Model of Graves' Orbitopathy. Invest Ophthalmol Vis Sci (2016) 57(10):4027-34.

Conflict of Interest: The authors declare that the research was conducted in the absence of any commercial or financial relationships that could be construed as a potential conflict of interest.

Copyright (C) 2021 Virakul, Somparn, Pisitkun, van der Spek, Dalm, Paridaens, van Hagen, Hirankarn, Palaga and Dik. This is an open-access article distributed under the terms of the Creative Commons Attribution License (CC BY). The use, distribution or reproduction in other forums is permitted, provided the original author(s) and the copyright owner(s) are credited and that the original publication in this journal is cited, in accordance with accepted academic practice. No use, distribution or reproduction is permitted which does not comply with these terms. 